



\section{THE ENABLING ENVIRONMENT FOR DISASTER RISK FINANCING IN SRI LANKA}

COUNTRY DIAGNOSTICS ASSESSMENT

FEBRUARY 2019 
(C) 2019 Asian Development Bank

6 ADB Avenue, Mandaluyong City, 1550 Metro Manila, Philippines

Tel +632632 4444; Fax +6326362444

www.adb.org

Some rights reserved. Published in 2019.

ISBN 978-92-9261-508-6 (print), 978-92-9261-509-3 (electronic)

Publication Stock No. TCS190010-2

DOI: http://dx.doi.org/10.22617/TCS190010-2

The views expressed in this publication are those of the authors and do not necessarily reflect the views and policies of the Asian Development Bank (ADB) or its Board of Governors or the governments they represent.

ADB does not guarantee the accuracy of the data included in this publication and accepts no responsibility for any consequence of their use. The mention of specific companies or products of manufacturers does not imply that they are endorsed or recommended by $\mathrm{ADB}$ in preference to others of a similar nature that are not mentioned.

By making any designation of or reference to a particular territory or geographic area, or by using the term "country" in this document, ADB does not intend to make any judgments as to the legal or other status of any territory or area.

This work is available under the Creative Commons Attribution 3.0 IGO license (CC BY 3.0 IGO)

https://creativecommons.org/licenses/by/3.0/igo/. By using the content of this publication, you agree to be bound by the terms of this license. For attribution, translations, adaptations, and permissions, please read the provisions and terms of use at https://www.adb.org/terms-use\#openaccess.

This CC license does not apply to non-ADB copyright materials in this publication. If the material is attributed to another source, please contact the copyright owner or publisher of that source for permission to reproduce it. ADB cannot be held liable for any claims that arise as a result of your use of the material.

Please contact pubsmarketing@adb.org if you have questions or comments with respect to content, or if you wish to obtain copyright permission for your intended use that does not fall within these terms, or for permission to use the ADB logo.

Corrigenda to ADB publications may be found at http://www.adb.org/publications/corrigenda.

Notes:

In this publication, "\$” refers to United States dollars.

ADB recognizes "Ceylon” as Sri Lanka.

On the cover (from left to right): A man anguishes as he searched in the remains of his house after a massive tsunami hit Kalutura, Sri Lanka on 30 December 2004. Thousands were killed when a magnitude 9.0 earthquake spawned off in Indian Ocean caused a tsunami in coastal areas in India, Indonesia, Sri Lanka and Thailand. Sri Lankan army members and civil volunteers distribute aid to flood affected victims in Wellampitiya (outskirts of Colombo), Sri Lanka on 20 May 2016 (photos by Scott Barbour/Getty Images; Chamila Karunarathne/Anadolu Agency/Getty Images). 


\section{Contents}

Tables, Figures, and Boxes iv

Acknowledgments $\mathrm{v}$

Currency Equivalent vii

Abbreviations vii

Executive Summary viii

1. Introduction 1

1.1 Background 1

1.2 Risk Layering Approach 2

1.3 Country Diagnostics Methodology 4

2. The Public Sector Disaster Risk Financing Landscape 8

2.1 Landscape Overview 8

$\begin{array}{ll}2.2 & \text { Diagnostic and Recommended Actions } \\ \end{array}$

3. Diagnostic on the Current Availability and Use of Insurance, Reinsurance, 16 and Capital Market Solutions for Disaster Risk Financing

$\begin{array}{lll}3.1 & \text { Government Policy } & 17\end{array}$

3.2 Credibility of the Private Sector Offering Risk Transfer Solutions 23

$\begin{array}{lll}3.3 & \text { Product Availability and Affordability } & 36\end{array}$

3.4 Social Protection $\quad 43$

4. The Rating Summary and Recommended Main Actions 46

4.1 Gaps in, and Recommendations for, Government Policy 47

4.2 Gaps in, and Recommendations for, Credibility in the Insurance Sector 47 and the Capital Markets

4.3 Gaps in, and Recommendations for, Products 48

4.4 Gaps in, and Recommendations for, Social Protection 49

4.5 Gaps in, and Recommendations for, Economic and Other Preconditions 49

4.6 Gaps in, and Recommendations for, Unlicensed Competition 50

APPENDIX: Key Learnings from International Experience 51 in Agricultural Insurance

References 


\section{Tables, Figures, and Boxes}

Tables

1 Key Agricultural Indicators of Sri Lanka $\quad 18$

2 Damage and Loss in the Agricultural Sector 19

3 Total Gross Premiums Recorded by the Insurance Industry, 2012-2016 24

4 Key Microinsurance Indicators in Sri Lanka, 2015 31

5 Microinsurance Products in Sri Lanka, 2015 32

6 Key Agricultural Insurance Products Offered in Sri Lanka 39

7 Size and Composition of Capital Markets of Sri Lanka in $2016 \quad 40$

\section{Figures}

$1 \quad$ Layered Approach to Disaster Risk Financing 3

2 The W\&W Insurance, Reinsurance, and Capital Markets Solutions 7

Development Framework (Hypothetical Example)

3 Sri Lanka Gross Domestic Product Growth, 2012-2018 11

4 Structure of the Sri Lanka Disaster Management System 13

5 The Rating Results for Sri Lanka $\quad 16$

6 Flow of Crop Insurance Levy 21

7 The Rating Results for Sri Lanka 46

\section{Boxes}

1 Examining the Full Sovereign Disaster Risk Financing Landscape $\quad 5$

2 Traditional Insurance Products Available in Sri Lanka 37 


\section{Acknowledgments}

This report was prepared under the Technical Assistance (TA) 9007: Strengthening the Enabling Environment for Disaster Risk Financing (Phase 1). The TA was executed by Asian Development Bank (ADB) in collaboration with the Government of Sri Lanka.

Charlotte Benson, Principal Disaster Risk Management Specialist, Climate Change and Disaster Risk Management Division, Sustainable Development and Climate Change Department (SDCC), ADB; and Arup Chatterjee, Principal Financial Sector Specialist, Financial Sector Advisory Service Cluster, SDCC, ADB, provided direction and technical advice for this report.

The report was produced by a team of ADB consultants comprising Rodolfo Wehrhahn, Team Leader, Insurance and Capital Market Regulatory Specialist (International Consultant); Nasreen Rashid, Disaster Risk Insurance Specialist (International Consultant); Mayur Ankolekar, Agriculture Insurance Specialist (International Consultant); Ainsley Alles, Insurance Industry Specialist (National Consultant); and Maria Cristina Pascual, Project Coordinator (National Consultant).

The team wishes to thank the South Asia Department colleagues in ADB for their advice and support during the mission, particularly Sri Widowati, Country Director of Sri Lanka Resident Mission (SLRM); Bruno Carrasco, Director, Public Management, Financial Sector \& Trade Division (SAPF); Mayumi Ozaki, Senior Portfolio Management Specialist, SAPF; and Yazeem Bawa Mohamed Asmi, Project Analyst, SLRM.

The report benefited extensively from the kind interaction with many key organizations to whom the team would like to express great appreciation to the following for their time and candid opinions:

\section{Government Agencies of Sri Lanka}

Central Bank of Sri Lanka

Insurance Regulatory Commission of Sri Lanka (formerly the Insurance Board of Sri Lanka)

Ministry of Agriculture

Ministry of Finance and Planning

Department of National Budget

Department of Treasury Operations

Ministry of Provincial Councils and Local Government

Ministry of Disaster Management

Department of Meteorology

National Council for Disaster Management

Ministry of National Policies and Economic Affairs

Ministry of Power and Renewable Energy

Ministry of Social Empowerment 
Ministry of Transport and Civil Aviation

Securities and Exchange Commission of Sri Lanka

\section{Statutory Bodies}

Agricultural and Agrarian Insurance Board

National Insurance Trust Fund

Sri Lanka Tea Board

Tea Smallholdings Development Authority

\section{Private Sector}

Actuarial Association of Sri Lanka

Allianz Insurance Lanka Limited

Amãna Takaful PLC

Fairfirst Insurance (formerly Union Assurance General Insurance and Asian Alliance General Insurance)

Ceylinco General Insurance Limited

Continental Insurance Lanka Limited

Cooperative Insurance Company Limited

Delmege Insurance Brokers (Pvt) Limited

Fitch Ratings Lanka Limited

HNB General Insurance Limited

Insurance Association of Sri Lanka

Janashakthi Insurance PLC

LOLC General Insurance Company Limited

MBSL Insurance Company Limited

Orient Insurance Limited

Peoples Insurance Company Limited

Sanasa Insurance Company Ltd.

Senaratne Insurance Brokers (Pvt) Limited

Sri Lanka Export Credit Insurance Corporation

Sri Lanka Insurance Corporation Limited

Sri Lanka Microfinance Practitioners' Association

Union Assurance General Limited 


\section{Currency Equivalent}

(as of 31 March 2017)

$\begin{array}{lll}\text { Currency Unit } & - & \text { Sri Lanka rupee (SLR) } \\ \text { SLRs1.00 } & = & \$ 0.00657 \\ \$ 1.00 & = & \text { SLRs152.12 }\end{array}$

\section{Abbreviations}

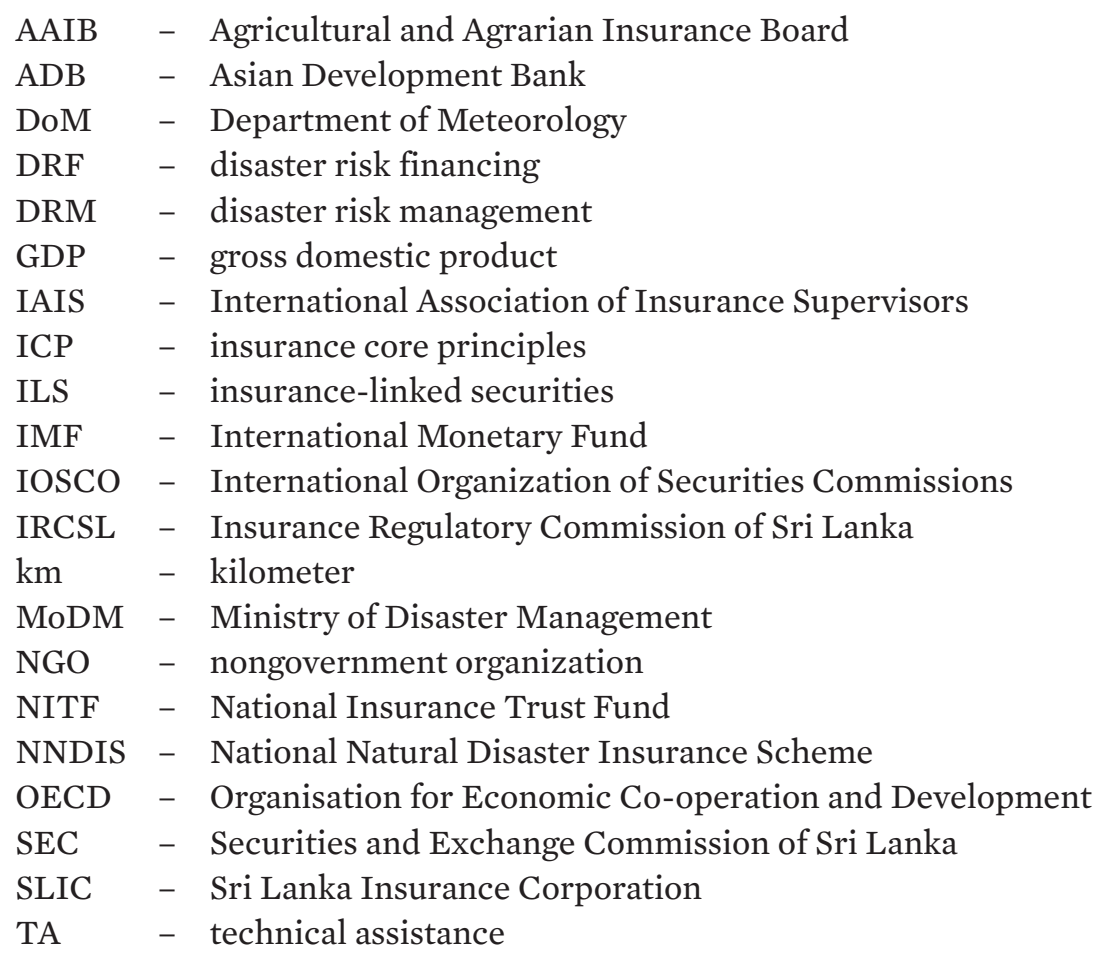




\section{Executive Summary}

This country diagnostic assessment reviews the current disaster risk financing (DRF)

- landscape and enabling environment in Sri Lanka with a focus on risk transfer instruments-insurance, reinsurance, and capital markets.

The assessment is based on a modified version of the $\mathrm{W} \& \mathrm{~W}$ development framework for accommodating international best practice and public and private sector stakeholders' inputs. This allows insight into existing and perceived demand and supply factors that shape the development of an enabling environment for DRF in Sri Lanka. Within this framework, six areas relevant to the development of insurance and capital market solutions for DRF are reviewed: (i) government policy; (ii) economic conditions; (iii) disaster risk product availability and affordability; (iv) credibility of the insurance, reinsurance, and capital markets providers; (v) social protection policy; and (vi) unlicensed competition.

The assessment identifies gaps and opportunities for enhancing the enabling environment for public and private sector DRF solution, including insurance, reinsurance, and capital market solutions. It includes recommendations to improve the DRF enabling environment.

The diagnostics tool and a toolkit that describes the proposed enabling environment actions and their importance, the DRF tools and instruments of general use, including a glossary of technical terms, completes the suite of documents of this technical assistance. 


\section{Table: Key Recommendations for the Strengthening of the Enabling Environment for Disaster Risk Financing}

\begin{tabular}{|c|c|c|c|}
\hline Recommendations & Responsible Body & Timing ${ }^{\mathrm{a}}$ & $\begin{array}{l}\text { Reference in } \\
\text { the Report }\end{array}$ \\
\hline $\begin{array}{l}\text { 1. Implement the National } \\
\text { Disaster Fund to streamline } \\
\text { disaster-related expenditures }\end{array}$ & $\begin{array}{l}\text { Ministry of Disaster } \\
\text { Management }\end{array}$ & Near term & para. 41 \\
\hline $\begin{array}{l}\text { 2. Develop a comprehensive } \\
\text { disaster risk model and } \\
\text { mapping }\end{array}$ & $\begin{array}{l}\text { Insurance Association } \\
\text { of Sri Lanka, Ministry of } \\
\text { Disaster Management }\end{array}$ & Near term & para. 43 \\
\hline $\begin{array}{l}\text { 3. Develop a disaster risk } \\
\text { financing strategy following the } \\
\text { risk layering approach }\end{array}$ & $\begin{array}{l}\text { Ministry of Disaster } \\
\text { Management }\end{array}$ & Near term & para. 42 \\
\hline $\begin{array}{l}\text { 4. Quantify government-owned } \\
\text { infrastructure and assets } \\
\text { exposure to disasters and decide } \\
\text { on their respective levels of } \\
\text { protection }\end{array}$ & $\begin{array}{l}\text { Ministry of Public } \\
\text { Administration }\end{array}$ & Medium term & para. 44 \\
\hline $\begin{array}{l}\text { 5. Consider disaster contingent } \\
\text { loans }\end{array}$ & $\begin{array}{l}\text { Ministry of Finance and } \\
\text { Planning }\end{array}$ & Medium term & para. 45 \\
\hline $\begin{array}{l}\text { 6. Formulate a government policy } \\
\text { on the use of risk transfer } \\
\text { instruments for DRF }\end{array}$ & Government of Sri Lanka & Near term & para. 63 \\
\hline $\begin{array}{l}\text { 7. Adopt a coordinated approach } \\
\text { to the crop insurance levy's } \\
\text { accumulated fund and subsidies }\end{array}$ & Government of Sri Lanka & Medium term & para. 64 \\
\hline $\begin{array}{l}\text { 8. Explore a provision for } \\
\text { insurance for smallholder tea } \\
\text { growers }\end{array}$ & Government of Sri Lanka & Medium term & para. 67 \\
\hline $\begin{array}{l}\text { 9. Expand the number of } \\
\text { automated weather stations and } \\
\text { weather forecasting skill sets }\end{array}$ & Department of Meteorology & Medium term & $\begin{array}{l}\text { paras. } 66 \\
\text { and } 110\end{array}$ \\
\hline $\begin{array}{l}\text { 10. Carry out a successful } \\
\text { assessment of insurance } \\
\text { regulatory framework against } \\
\text { the insurance core principles of } \\
\text { the International Association of } \\
\text { Insurance Supervisors }\end{array}$ & $\begin{array}{l}\text { Insurance Regulatory } \\
\text { Commission of Sri Lanka }\end{array}$ & Medium term & para. 102 \\
\hline $\begin{array}{l}\text { 11. Implement the } \\
\text { recommendations of the } 2016 \\
\text { Asian Development Bank } \\
\text { assessment of the capital } \\
\text { markets }\end{array}$ & $\begin{array}{l}\text { Securities Exchange } \\
\text { Commission of Sri Lanka, } \\
\text { Government of Sri Lanka }\end{array}$ & Near term & para. 105 \\
\hline $\begin{array}{l}\text { 12. Strengthen the capacity and } \\
\text { transparency of the National } \\
\text { Insurance Trust Fund, and } \\
\text { enhance its retrocession } \\
\text { procurement process }\end{array}$ & $\begin{array}{l}\text { National Insurance Trust } \\
\text { Fund, Government of } \\
\text { Sri Lanka }\end{array}$ & Medium term & para. 106 \\
\hline
\end{tabular}




\section{Table continued}

\begin{tabular}{|c|c|c|c|}
\hline Recommendations & Responsible Body & Timing ${ }^{\mathrm{a}}$ & $\begin{array}{c}\text { Reference in } \\
\text { the Report }\end{array}$ \\
\hline $\begin{array}{l}\text { 13. Balance the mix of Sri Lanka } \\
\text { Insurance Corporation's } \\
\text { investment assets and carry out } \\
\text { an assessment of its liquidity } \\
\text { risk }\end{array}$ & $\begin{array}{l}\text { Sri Lanka Insurance } \\
\text { Corporation, Ltd., Ministry } \\
\text { of Public Enterprise } \\
\text { Development, Ministry of } \\
\text { Finance and Planning }\end{array}$ & Near term & para. 107 \\
\hline $\begin{array}{l}\text { 14. Create a level playing field in } \\
\text { the insurance and reinsurance } \\
\text { sectors }\end{array}$ & $\begin{array}{l}\text { Insurance Regulatory } \\
\text { Commission of Sri Lanka, } \\
\text { Government of Sri Lanka }\end{array}$ & Medium term & para. 108 \\
\hline $\begin{array}{l}\text { 15. Supervise the insurance } \\
\text { activities of the Agricultural and } \\
\text { Agrarian Insurance Board }\end{array}$ & $\begin{array}{l}\text { Insurance Regulatory } \\
\text { Commission of Sri Lanka, } \\
\text { Government of Sri Lanka }\end{array}$ & Medium term & para. 108 \\
\hline $\begin{array}{l}\text { 16. Separate the agricultural } \\
\text { insurance and pension provision } \\
\text { activities of the Agricultural and } \\
\text { Agrarian Insurance Board }\end{array}$ & $\begin{array}{l}\text { Agricultural and Agrarian } \\
\text { Insurance Board, } \\
\text { Government of Sri Lanka }\end{array}$ & Medium term & para. 109 \\
\hline $\begin{array}{l}\text { 17. Maintain continuity in the } \\
\text { National Natural Disaster } \\
\text { Insurance Scheme at a } \\
\text { reasonable price }\end{array}$ & $\begin{array}{l}\text { National Insurance Trust } \\
\text { Fund, Government of Sri } \\
\text { Lanka }\end{array}$ & Near term & para. 130 \\
\hline $\begin{array}{l}\text { 18. Introduce mandatory } \\
\text { environmental liability } \\
\text { insurance }\end{array}$ & Government of Sri Lanka & Medium term & para. 131 \\
\hline $\begin{array}{l}\text { 19. Consider insurance-linked } \\
\text { securities, including catastrophe } \\
\text { bonds, as additional DRF } \\
\text { instruments }\end{array}$ & $\begin{array}{l}\text { Ministry of Finance and } \\
\text { Planning }\end{array}$ & Medium term & para. 133 \\
\hline $\begin{array}{l}\text { 20.Incorporate all insurance } \\
\text { providers into a proportionate } \\
\text { regulatory regime under the } \\
\text { purview of the Insurance } \\
\text { Regulatory Commission of } \\
\text { Sri Lanka }\end{array}$ & $\begin{array}{l}\text { Insurance Regulatory } \\
\text { Commission of Sri Lanka }\end{array}$ & Near term & para. 141 \\
\hline
\end{tabular}

$\mathrm{DRF}=$ disaster risk financing.

a "Near term" is within 1 year; "Medium term" is $1-3$ years.

Source: Asian Development Bank. 


\section{Introduction}

\subsection{Background}

1. Disasters delay long-term development and hamper efforts to reduce poverty in the Asian Development Bank's (ADB) developing member countries. Disasters set back development, directly damaging and destroying infrastructure and disrupting related economic activities and the provision of services. They place countries on lower long-term growth trajectories, push vulnerable communities deeper into poverty, and force adjustments in both short- and longer-term development targets and goals. They can place significant fiscal strain on governments, businesses, and individual households, particularly if financial preparedness arrangements are limited. Funding delays and shortages can significantly exacerbate the consequences of direct physical losses, extending the time to rebuild. Government officials, policy makers, and insurance regulators from developing Asia and the Pacific have therefore expressed the need to strengthen their countries' financial preparedness for disasters, smoothing the cost of disasters over time, and ensuring timely availability of post-disaster funding. ${ }^{1}$ A strong enabling environment for disaster risk financing (DRF), including for the stimulation of commercial risk transfer markets, is a priority prerequisite for achieving this result.

2. Enhanced financial preparedness for disasters is an ADB priority. The ADB technical assistance (TA) project, Strengthening the Enabling Environment for Disaster Risk Financing (ADB 2015) under which this document is prepared, is consistent with ADB's Operational Plan for Integrated Disaster Risk Management, 2014-2020, which supports "the development of DRF instruments and wider DRF strategies for households, businesses, and governments, enhancing the public and private financial management of residual disaster risk." It is also consistent with the Review of the 2011 Financial Sector Operational Plan (ADB 2017c), which calls for building capabilities in emerging and innovative finance areas such as DRF.

3. ADB's holistic approach to DRF is reflected in this TA. ADB strongly advocates an integrated approach to disaster risk management (DRM), seeking to strengthen disaster resilience both through disaster risk reduction and the enhanced management of residual risk. ADB is seeking to enhance financial preparedness for disaster as part of broader efforts

1 For example, these views were expressed at two events that ADB organized in partnership with the Organisation for Economic Co-operation and Development (OECD) to exchange knowledge and practices on financial protection against disaster risks among officials and experts from ADB, Asia-Pacific Economic Cooperation (APEC), Association of Southeast Asian Nations (ASEAN), governments in Asia and elsewhere, and the insurance industry. These events comprised (i) an ADB-OECD Forum on Disaster Risk Financing for Inclusive Development held on 15-16 September 2015 in Manila, Philippines; and (ii) an ADB-OECD Global Seminar on Disaster Risk Financing: Developing Effective Approaches to the Financial Management of Disaster Risks held on 17-18 September 2015 in Kuala Lumpur, Malaysia.

2 ADB. 2014. Operational Plan for Integrated Disaster Risk Management, 2014-2020. Manila. page 15. 
to strengthen disaster resilience. It is doing so in close coordination with governments, global and regional DRF initiatives, ${ }^{3}$ standard-setting bodies such as the International Association of Insurance Supervisors (IAIS), International Organization of Securities Commissions (IOSCO), the Basel Committee on Banking Supervision, the Financial Stability Institute, and the insurance industry. Disaster risk reduction efforts should be the first option for consideration in addressing disaster risk, tackling the root causes of the issue. DRF solutions should also conform to international financial standards and be designed around the context of broader disaster resilience, financial stability, and financial inclusion, incorporating incentives for disaster risk reduction. This approach should lead to the development and implementation of financially sustainable, scalable DRF strategies and solutions. ADB applies a risk-layering approach to support the appropriate selection of DRM options, including DRF instruments (section 1.2).

4. This country diagnostic assessment identifies areas of improvement to promote an enhanced enabling environment for DRF in Sri Lanka. The country was selected for inclusion in the TA in part because of its significant disaster risk, but also-more positivelybecause of its middle-income status and expanding economy, providing a strong basis for the emergence of viable market-based risk transfer solutions. The country diagnostic assessment is expected to facilitate the development and implementation of appropriate instruments for different layers of risk. It identifies areas of improvement to enhance the enabling environment for public and private sector DRF solution, ${ }^{4}$ including insurance, reinsurance, and capital market solutions.

5. Recommendations based on the assessment are comprehensively presented at the end of the section of each axis. The recommended series of activities and measures to enhance the enabling environment for key public sector DRF instruments as well as insurance, reinsurance, and capital markets solutions.

\subsection{Risk Layering Approach}

6. Disaster resilience begins with risk reduction, that is, acting to reduce levels of loss in the event of natural hazards. However, disaster risk cannot be eliminated, so investment in financial preparedness for disasters also needs to be enhanced, seeking to ensure that sufficient financing is available to support timely relief, early recovery, and reconstruction efforts.

7. Governments can draw on an array of instruments to support enhanced financial preparedness. These instruments are ideally applied using a risk layering approach, breaking disaster risk down according to the frequency of occurrence of different types of hazard events of varying severity and associated levels of loss, and designing bundles of instruments targeting differentiated layers of risk (ADB 2014). Governments should seek to select the most appropriate instruments for each layer of loss based on a range of factors including the

3 The Vulnerable Twenty (V20) Group; the Disaster Risk Financing and Insurance Program (DRFIP), a partnership of the World Bank's Finance and Markets Global Practice and the Global Facility for Disaster Reduction and Recovery (GFDRR); the Pacific Disaster Risk Financing and Insurance Program; and the G20/OECD Methodological Framework for Disaster Risk Assessment and Risk Financing.

4 See the stakeholder consultations of 2016 World Bank fiscal disaster risk assessment for Sri Lanka, which considerably informed this work (World Bank 2016a). 
scale of funding needed, the speed with which disbursement is required, and the relative cost-effectiveness of alternative instruments for specific layers of risk.

8. DRF instruments for residual risk begin with risk retention instruments for more frequent, less damaging events (Figure 1). These include annual contingency budget allocations, disaster reserves, and contingent credit arrangements, all of which can be put in place before disasters strike. In the aftermath of an event, governments can also reallocate budgets, increase borrowing, and raise taxes to provide additional resources.

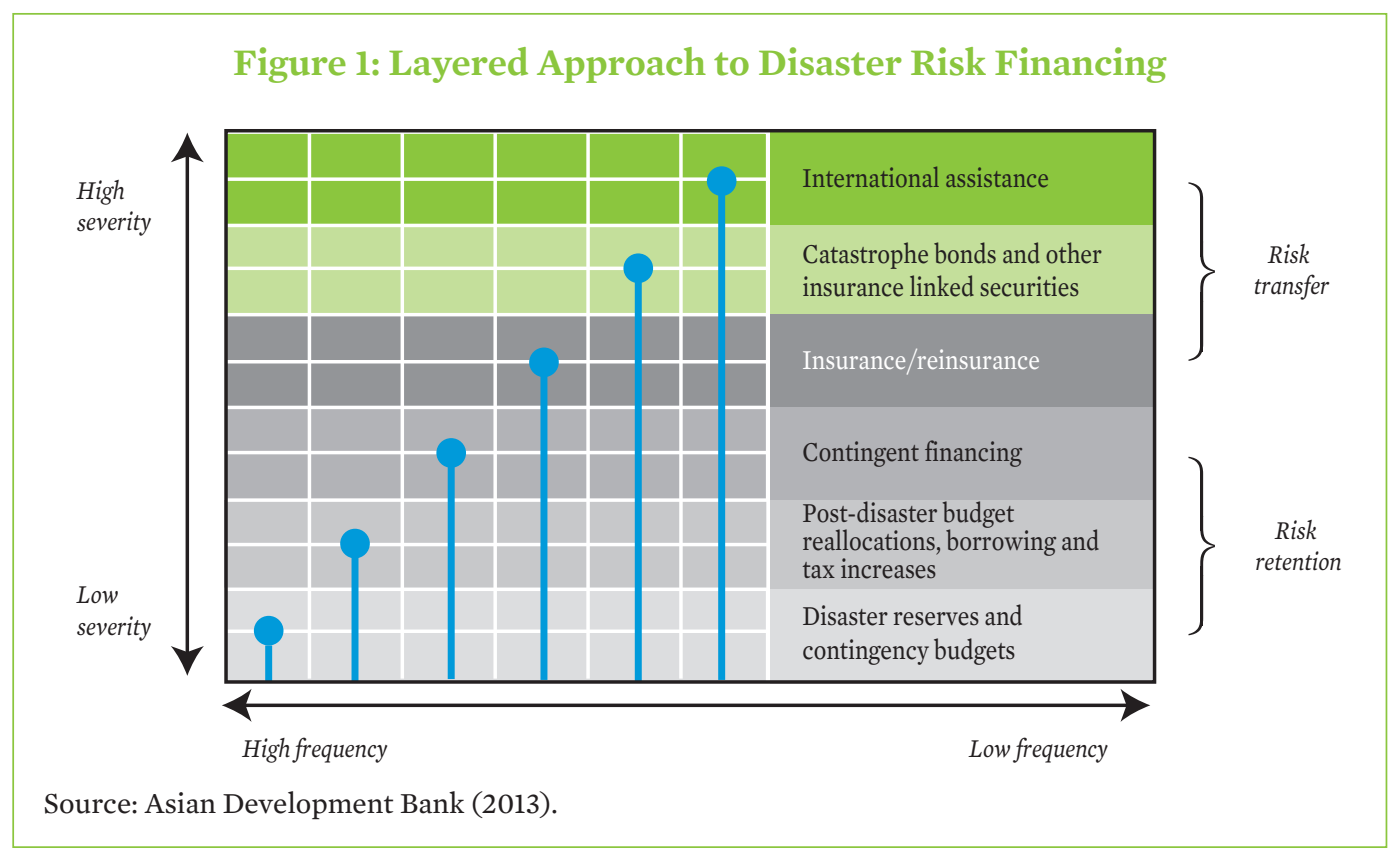

9. Market-based risk transfer solutions provide more cost-efficient financing for medium-level risks, which generate higher levels of loss but less frequently. These include insurance and insurance-linked securities, such as catastrophe bonds, and are taken out in anticipation of disasters. In the event of major disasters, governments also appeal to the international community for assistance.

10. DRF is not only a government responsibility. The private sector and individuals should be encouraged and enabled to strengthen their financial resilience to disasters as well. A similar risk layering approach is applicable for these groups. Decisions on reduction, retention, and transfer of disaster risk should be made within the structure of this broader framework, and appropriate instruments selected for each layer of risk.

11. The availability and assortment of instruments selected for a DRF strategy depend on a range of factors. The most appropriate bundle of instruments depends on (i) the scale of resources required at each layer of loss relative to the scale of resources that each instrument can facilitate access to; (ii) the speed with which funds are required relative to the speed of disbursement of each instrument; (iii) the marginal cost of each instrument; (iv) individual country circumstances, including prevailing macroeconomic circumstances; (v) the scale of potential events relative to gross domestic product (GDP); (vi) government 
economic, fiscal, and monetary goals and objectives; (vii) access to international finance markets; and (viii) the market-based cost of borrowing (ADB 2013). For example, if probable maximum losses from extreme events are low relative to GDP, then a country is better able to retain risk. A country with low indebtedness can rely more heavily on post-disaster borrowing than one with a higher level of indebtedness. Crucially, the effectiveness of disaster risk transfer instruments also depends on the availability of well-developed and sound domestic insurance and capital market sectors. Among other issues, cultural and religious dimensions are important, while it should be noted that government policy could crowd out the private insurance sector.

\subsection{Country Diagnostics Methodology}

\subsubsection{Diagnostics Tool}

12. A diagnostics tool was developed to conduct country assessments. Based on a modified version of the $\mathrm{W} \& \mathrm{~W}$ development framework, it provides a methodology for assessing the DRF landscape and its enabling environment. It is composed of a series of questions intended to identify both gaps between international best practice and the country situation, and opportunities for enhancement. It focuses on six areas of relevance for the development of disaster insurance and capital market solutions:

(i) Government policy regarding the development of risk transfer instruments for DRF, including the introduction of mandatory insurance protection, risk pooling structures, and insurance-linked securities (ILS); pertinent regulations; and the creation of a level playing field for insurance, reinsurance, and capital market activities.

(ii) Economic conditions and other support functions that influence the decision for retaining the risk rather than purchasing insurance, reinsurance, and capital market products (e.g., legal framework, data availability).

(iii) Disaster risk product availability and affordability, including products for corporations, individual households, and low-income populations.

(iv) Credibility of the private sector offering risk transfer solutions that cover aspects such as the regulatory environment, the solvency of risk carriers, the reputation of insurance and capital markets, and the availability of infrastructure (e.g., financial transaction platforms, and support from professionals such as actuaries, risk assessors, auditors, dealer brokers, and stock brokers).

(v) Social protection policy, recognizing that low-income populations should enjoy social protection or support in obtaining insurance coverage while insurance solutions for people who can afford premiums should not be crowded out, and exploring the degree to which social protection complements or crowds out marketbased solutions.

(vi) Unlicensed competition, recognizing that insurance credibility and resilient insurance providers are important, and examining the licensing and supervision of insurance providers by the regulator.

13. The diagnostics tool generates an overview of current policies and mechanisms for DRF. It identifies enabling conditions for the effective use of well-established DRF instruments and existing related barriers or gaps; sets policy priorities for implementing 
reforms and introducing new DRF instruments; and provides the basis for new or deeper engagement on DRF by governments, regulators, and development partners as part of a broader DRM and/or public financial management dialogue. The findings of the diagnostic can feed directly into the development of DRF strategies to enhance financial preparedness.

14. The diagnostics tool focuses on an assessment of disaster risk transfer instruments, covering both sovereign and nonsovereign instruments. Governments can play an important role in providing an adequate enabling environment for nonsovereign insurance, such as homeowner and commercial property insurance, business interruption cover, and crop insurance. In the process, they can reduce the contingent liability falling on government in the event of a disaster. Tools used for self-insurance or disaster risk retention by the government are mentioned, but not addressed in any depth as these are covered in a complementary tool developed by ADB and the World Bank (2017) (Box 1).

15. A fuller description of the tool, including the questions under each of the six areas of relevance, is presented in a companion document produced under the TA (ADB, forthcoming). The document also presents a generic tool kit for disaster insurance, reinsurance, and capital market solutions, including a glossary of technical terms, focusing on actions to strengthen the enabling environment to support potential DRF instruments.

\section{Box 1: Examining the Full Sovereign Disaster Risk Financing Landscape}

The Asian Development Bank and the World Bank disaster risk financing diagnostic assesses existing levels of financial protection against disasters to identify opportunities for enhancement. It contains questions for ministries of finance that were drawn from, and extend, the country analyses done under the current TA to build a fuller picture of the state of sovereign disaster risk financing arrangements, including risk retention mechanisms. These questions cover the following issues:

1. Assessment of fiscal shocks associated with disasters:

(i) contingent liability of the government,

(ii) fiscal risk assessment of disaster shocks, and

(iii) public disclosure of disaster-related fiscal exposure.

2. Ex ante disaster risk financing:

(i) annual contingency budget,

(ii) dedicated budget lines for disaster risk reduction,

(iii) dedicated disaster reserve funds,

(iv) line agency funding,

(v) contingent financing arrangements,

(vi) insurance of public assets,

(vii) any other forms of sovereign insurance, and

(viii) risk transfer arrangements through capital markets.

3. Ex post disaster risk financing:

(i) post-disaster budget reallocations,

(ii) external assistance, and

(ii) other ex post mechanisms. 


\subsubsection{Application of the Diagnostics Tool}

16. The diagnostics tool is used to determine and confirm existing DRF practices and gain insight into existing or perceived barriers hindering the development of DRF tools. The diagnostics tool is applied through a combination of desk work, stakeholder questionnaires, interviews, and group discussion. This wide-ranging approach is taken to accommodate the international best practice of countries with successful results and expert judgement on the actions needed to better enable effective use of DRF instruments. The basic steps are as follows:

(i) The assessors begin the diagnostics by gathering background information on the DRF strategy of the country, drawing from extensive publications, government websites, insurance and reinsurance industry documents, and capital market analyses.

(ii) The assessors then complement the background information by asking relevant stakeholders to answer extensive questionnaires on areas relevant to the DRF strategy and instruments used in the country. These questionnaires are integral to the diagnostics tool, and the insights gained from them are critical to conduct a robust assessment. The questions should be carefully explained to the stakeholders to stress the importance of providing comprehensive and open answers.

(iii) On-site interviews are conducted with selected stakeholders from both the public sector and the insurance, reinsurance, and capital market stakeholders, including actuaries, rating agencies, brokers, and auditing firms. These interviews enhance and complete the information gathered through the desk analysis and the questionnaire responses.

(iv) The comprehensive information is then analyzed and the gaps between international best practice and current practices identified.

(v) The recommended actions are discussed with the stakeholders and the feasibility and relevance of these recommendations are confirmed before the country diagnostic is finalized.

(vi) The recommendations are then implemented.

17. It is not expected that stakeholder will respond to all questions. Experience shows that the questionnaire will provide wide ranging responses, including contradicting statements, and some questions will remain unanswered. The assessors need to judge and filter the information to draw conclusions, but will also need to verify these conclusions with the stakeholders repeatedly, and provide recommendations only after such verification.

\subsubsection{Presentation of the Diagnostic Results}

18. The country diagnostics reports begin by presenting findings on the broad public sector DRF landscape, including related recommendations. The results of the diagnostic analysis are then presented and finally summarized in a spider diagram depicting country scoring for each of the six key areas of relevance for the development of disaster insurance and capital market solutions (Figure 2). For each area, the ideal, realistic, and current states of the enabling environment are depicted.

19. The ideal enabling conditions for the development of insurance, reinsurance, and capital market solutions for each of the six areas are defined. The assessors define this environment based on international best practice and expert judgement, as well as the political, cultural, and religious contexts of the marketplace. 


\section{Figure 2: The W\&W Insurance, Reinsurance, and Capital Markets Solutions Development Framework (Hypothetical Example)}

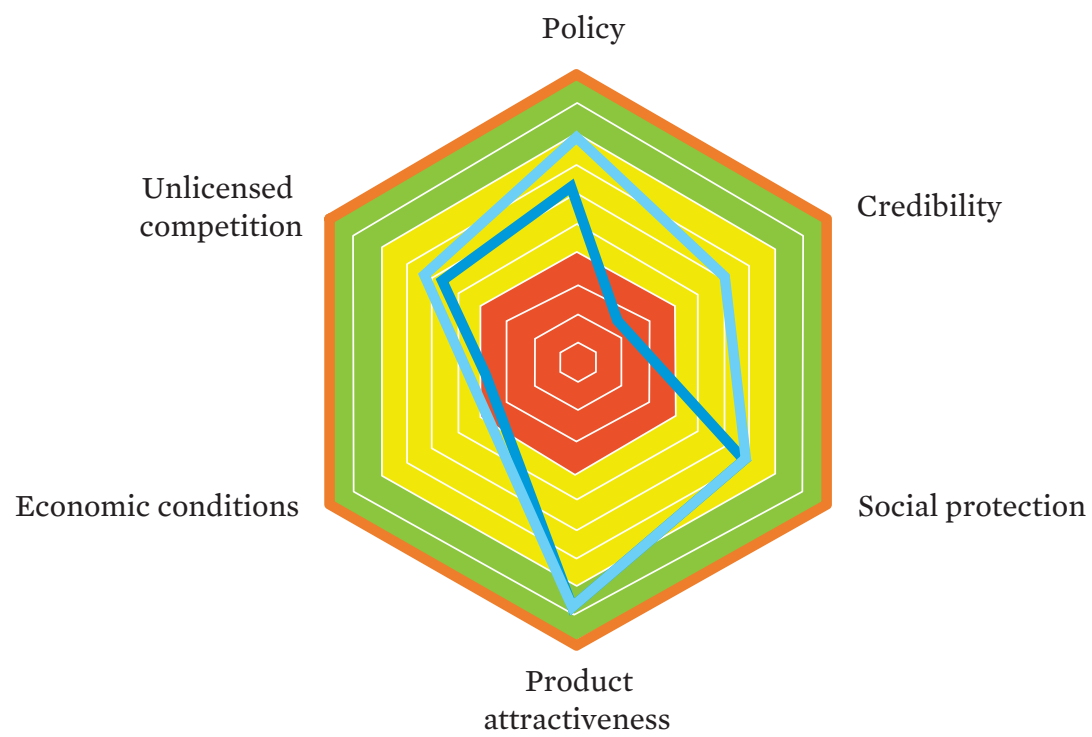

$\longrightarrow$ Enabling environment DRF IRCM existing environment

DRF IRCM realistic achievable environment

$\mathrm{DRF}=$ disaster risk financing, $\mathrm{IRCM}=$ insurance, reinsurance, and capital market.

Source: Asian Development Bank.

20. Enabling environment conditions that could be realistically achieved are also defined, recognizing that the ideal enabling environment may never be achieved. These are determined by drawing on local expertise as well as through extensive stakeholder consultation and analysis of the completed questionnaires to identify likely impediments to achieving the ideal enabling environment. The ideal and realistic enabling environments may not necessarily differ significantly from each other, as was found in the case of Sri Lanka.

21. The current environment for each of the axes is then populated, using local expertise and comments from relevant national stakeholders, including government authorities, private sector providers, and professional bodies.

22. The methodology used depicts the gaps between the current state of the enabling environment for disaster insurance, reinsurance, and capital market solutions, and the ideal and realistic alternatives. The comparison enables ready identification of areas for action, leading to the development of a strategy and road map to address the gaps. Actions to address the gaps should be prioritized depending on the scale of need and time frames for completion. Urgent actions are recommended to strengthen the enabling environment in the areas of relevance achieving scores of four or below (red); medium-term actions are needed for scores between four and six (yellow); and no immediate actions are required for higher scores (green). When the realistic enabling environment differs from the ideal scenario, that difference is considered when determining the urgency of the needed actions. The absolute scores have no further meaning and should not be used for cross-country comparisons. 


\section{The Public Sector Disaster Risk Financing Landscape}

\subsection{Landscape Overview}

23. Financing for disaster response presents an important challenge for the Government of Sri Lanka. Over the long term, Sri Lanka's housing, roads, and relief sectors alone experience a combined annual expected loss from disasters of $\$ 0.38$ billion, according to a World Bank study (2016a). The same study found that annual expected losses are highest for floods, with an annual expected loss of $\$ 0.24$ billion, followed by cyclones and high winds (with an AEL of $\$ 0.08$ billion). The World Bank estimates that the total average expected loss to all sectors lies in the region of $\$ 0.9-\$ 1.5$ billion. Probable maximum loss for 1-in-10 year events (i.e., for hazards with a $10 \%$ chance of occurrence each year) is in the order of $\$ 1.7-\$ 3.0$ billion. As the government conveyed to the ADB mission, the financial challenges in providing post-disaster assistance and the need to quantify contingent liabilities and postdisaster spending requirements to better manage budget risks need to be addressed.

24. The 2004 Indian Ocean tsunami was the largest and most devastating disaster in the history of Sri Lanka, resulting in total economic losses of $\$ 1.0$ billion (4.5\% of GDP) and estimated reconstruction needs of \$1.5-\$1.6 billion (ADB, JICA, and the World Bank 2005). The most severely affected coastal regions were still lagging behind the rest of the country a decade later (Zane 2010).

25. More recently, the country has experienced severe droughts in 2011 and 2016, and major floods and landslides in 2011, 2014, 2016, and 2017, with disproportionate impacts on the poor. The January 2011 floods caused over $\$ 600$ million in direct damages and affected over a million people in the Northern, North Central, and Eastern provinces. The 2016 and 2017 drought and floods disrupted two rice cultivation cycles and affected over 2 million people according to government estimates, curtailing economic growth and causing food inflation (IMF 2018). The severe droughts in 2011 and 2016 also resulted in a reduction in hydropower generation, leading to an increase in oil imports and thermal power generation, in turn undermining the stability of the balance of payments (Ministry of Planning and Finance 2012b, IMF 2018). Higher thermal power generation costs as a consequence of the 2016 drought also led to record financial losses by the Ceylon Electricity Board in the amount of SLRs34 billion (0.3\% of GDP) in the first half of 2017, resulting in government transfers to the Board totaling SLRs6 billion up to November 2017 alone (IMF 2018).

26. The government incurs further post-disaster fiscal pressures via significant postdisaster relief expenditure, both for humanitarian response and longer-term recovery. These costs, together with those for the rehabilitation of roads and irrigation systems, were estimated at SLRs50 billion (0.4\% of GDP) in 2017, including targeted income support for severely affected households through the provision of food vouchers and support for the construction of new houses (IMF 2018). 
27. The authorities relaxed 2017 fiscal targets due to the exceptionally severe weather events of 2016 and 2017, resulting in spending needs in excess of the space that could be generated by midyear budget reallocation and spending rationalization (IMF 2018). Some budget reallocations were also made to address the fiscal challenges. The government intends to avoid a similar situation in 2018 , in part via higher disaster provisions as well as more front-loaded fiscal consolidation (IMF 2018). It also launched a National Natural Disaster Insurance Scheme (NNDIS) in 2016 to help enhance the fiscal management of its postdisaster compensation to affected households (section 3.3.2).

28. The country's broader economic conditions are also challenging, complicating any efforts to establish ex ante DRF instruments and leaving the government less able to meet significant disaster response spending needs ex post. In June 2016, the International Monetary Fund (IMF) approved a 36-month extended fund facility arrangement to support the Sri Lanka's economic reform agenda, at which time it stated that

Sri Lanka has gone through a significant political transition against the backdrop of an increasingly difficult external environment. Two major elections in 2015 brought a new government to the helm, major constitutional changes (trimming the power of the presidency), and a reorganization of ministerial agency portfolios. At the same time, surging imports, falling exports, slowing remittances, tepid foreign direct investment, and a steady outward march of capital from government securities markets gave rise to macroeconomic imbalances. ${ }^{5}$

29. The government's strategy agreed with the IMF to address short-term imbalances and medium-term challenges rests on six pillars:

(i) Fiscal consolidation. Steady reduction of the government budget deficit to lower public debt, bolster investor confidence, and reduce government borrowing.

(ii) Revenue mobilization. Simplifying the tax system and broadening the tax base to ensure transparency and equity, and create space for spending on infrastructure and human capital.

(iii) Public financial management. Strong and consistent control over spending commitments to keep expenditures on target and eliminate waste. Budgets will be transparent and report on foregone revenue from tax exemptions and holidays, as well as risks from state-owned enterprises.

(iv) State enterprise reform. Oversight and financial discipline of state-owned enterprises (SOEs) will be bolstered. SOEs will be bound to a rules-based financial relationship with the central government while giving them sufficient autonomy to function on a commercial basis.

(v) Enhancing monetary policy. The Central Bank of Sri Lanka will seek to keep inflation low while transitioning to a more flexible exchange rate regime and a flexible inflation targeting framework.

(vi) Trade and investment facilitation. Reducing protectionism to enhance export opportunities, competitiveness, and help facilitate greater integration into global supply chains-supporting prospects for investment and growth. ${ }^{6}$

5 IMF. 2016. 'IMF Survey: Sri Lanka to Reboot Economic Policies'. IMF News. 24 June 2016 . https://www.imf.org/ en/News/Articles/2015/09/28/04/53/socar061416a.

6 Footnote 5. 
30. The country has achieved encouraging results to date, notwithstanding the additional challenges noted by the 2016 floods and 2017 droughts. The IMF (2017) states: Following the Executive Board's discussion of the review, Mr. Mitsuhiro Furusawa, Acting Chair and Deputy Managing Director, of the IMF said:

Sri Lanka's performance under the Fund-supported program has remained broadly on track since the second review. Macroeconomic and financial conditions have been stable, despite a series of weather-related supply shocks. The authorities remain committed to the economic reforms under the program and have undertaken measures to improve government revenue and accumulate international reserves. Going forward, it is important to build on the progress made and accelerate reforms to further reduce fiscal and external vulnerabilities. Fiscal performance has been satisfactory and all targets until September were met. The new Inland Revenue Act will make the tax system more efficient and equitable, and generate resources for social and development programs. Nevertheless, Sri Lanka's high debt burden, large gross financing needs, and weak financial performance of state-owned enterprises increases the importance of further fiscal consolidation. Timely progress in structural reforms, including tax administration and energy pricing, will support fiscal consolidation. ${ }^{7}$

31. The 2017 economic outlook as provided by ADB shows continued growth, following several years of steady progress as indicated in Figure 3. However, important challenges remain:

While global trade growth augurs well for industry in the second half, the forecast for GDP growth in 2017 is revised down by 0.5 percentage points. The higher forecast for 2018 is maintained as Sri Lanka pursues economic adjustment agreed with the International Monetary Fund. Food inflation peaked in April at $11.8 \%$ but remained high at $8.2 \%$ in July, when headline inflation softened to $6.3 \%$. Despite this moderation, higher than expected food inflation, on top of currency depreciation and higher value-added taxes prompts a 1.0 percentage point upgrade to the 2017 inflation forecast. Inflation is forecast to slow in 2018 in the wake of monetary tightening and a high base effect, downgrading the forecast by 2.0 percentage points... Although garment exports may improve in the second half, the forecast for the current account deficit in 2017 is revised up by more than half. The deficit is now expected to shrink in 2018 but remain wider than forecast in April. A \$1.5 billion sovereign bond issue and a $\$ 450$ million syndicated loan to the government helped to sustain gross international reserves at $\$ 7.0$ billion in June 2017. Sri Lankan rupee depreciation against the US dollar in the first 8 months of 2017 was modest at $2.9 \% .{ }^{8}$

7 IMF. 2017. IMF Executive Board Completes Third Review of the Extended Arrangement Under the EFF with Sri Lanka and Approves \$251.4 Million Disbursement. Press Release No. 17/470, 7 December. https://www.imf. org/en/News/Articles/2017/12/07/pr17470-imf-board-completes-third-review-of-the-extended-arrangementunder-the-eff-with-sri-lankal.

8 ADB. 2017b. Asian Development Outlook 2017 Update. page 174. 
Figure 3: Sri Lanka Gross Domestic Product Growth, 2012-2018

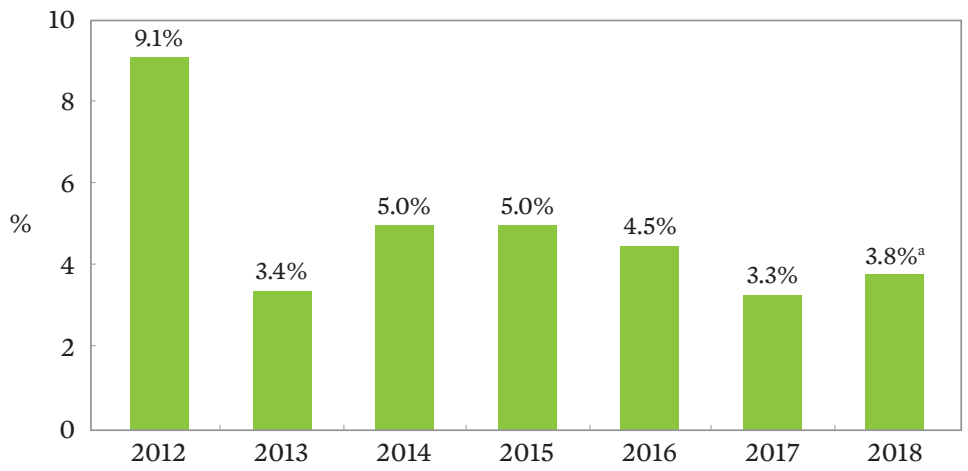

a ADB forecast.

Source: Asian Development Bank (2018a).

32. Nevertheless, the following targets for Sri Lanka at the end of the medium-term IMF program remain ambitious, particularly if further major disasters occur over the next few years:

(i) A fiscal deficit of $3.5 \%$ of GDP by 2020-sustained or lowered over the longer term to ensure the debt-to-GDP ratio continues to fall.

(ii) An increase in the tax-to-GDP ratio from $10.1 \%$ in 2014 to about $15 \%$ by 2020 .

(iii) A reduction in public debt to about $68 \%$ of GDP by 2020.

(iv) An increase in foreign exchange reserves of the central bank to about 5 months of import cover by the end of the medium-term.

\section{Policy Context}

33. The Disaster Management Act No. 13 of 2005 legally institutionalizes the disaster management system of Sri Lanka. It seeks to make disasters a national priority and forms the basis for the subsequent disaster risk management documents including the 2010 National Policy on Disaster Management; the 2015 Road Map for Disaster Risk Management; and the 2014-2018 Sri Lanka Comprehensive Disaster Management Programme.

34. Aligned to the Mahinda Chintana: Vision for Future (Ministry of Finance and Planning 2016), the country's prevailing development policy framework at that time, the 2010 National Policy on Disaster Management envisions a Sri Lanka safe from disaster by protecting people, property, and the environment, while considering the multidimensionality of disaster management; the collective responsibility of stakeholders; and the principles of equality, diversity, inclusion, transparency, and accountability (Ministry of Disaster Management 2010b).

35. The government's current long-term vision for the future continues to emphasize the importance of enhanced DRM. It recognizes that "weak environment and disaster management ha(ve) raised Sri Lanka's vulnerability to natural disasters" and that "the frequency of droughts, floods, and landslides impose a heavy human and financial burden 
falling mostly on less affluent sections of the population." ${ }^{9}$ To enhance disaster resilience, it indicates that a National Disaster Response Fund for financing post-disaster reconstruction will be established; that the government will resettle high-risk communities living in landslide-prone areas; that hazard, vulnerability, and risk assessments will be undertaken; that insurance schemes will be introduced for economically important sectors; and that flood mitigation projects within metropolitan areas will be expedited (Ministry of National Policies and Economic Affairs 2017c).

\section{Institutional Arrangements}

36. The National Council for Disaster Management (NCDM), chaired by the President and vice-chaired by the Prime Minister, is the principal body for DRM coordination and monitoring in the country. Having a corporate identity, it has its own administrative and financial processes to aid expeditious decision-making and action in the implementation of DRM activities. The Ministry of Disaster Management (MoDM), under the purview of the Prime Minister, acts as the secretariat of the council and directs the strategic process for disaster risk reduction, preparedness, and response.

37. Four important agencies function under the MoDM. These comprise of the Department of Meteorology (DoM), National Building Research Organization, National Disaster Relief Services Centre, and Disaster Management Centre, as outlined by the MoDM (Ministry of Disaster Management 2010). The full list of agencies under the MoDM is depicted in Figure 4.

(i) DoM provides meteorological, climatological and limited astronomical services; early warning services for meteorological hazards and tsunamis; and technical services on climate change (section 3.2.3).

(ii) The National Building Research Organization offers cutting edge technical services to promote a culture of disaster mitigation, preparedness, and safety through innovative disaster education, research, and training.

(iii) The National Disaster Relief Services Centre is responsible for disaster preparation, response, and recovery measures and is expected to have a fund allocation to ensure that pre- and post-disaster activities are managed effectively.

(iv) The Disaster Management Centre, as the operational arm, is responsible for planning, coordinating, and implementing DRM activities. Among its specific functions include (a) the implementation of the National Disaster Management Plan and the National Emergency Operation Plan and, in times of disaster, direction and coordination of the implementation of the National Emergency Operation Plan; (b) ensuring disaster management plans of national agencies and public corporations conform to the National Disaster Management Plan; (c) preparation and implementation of programs, plans, and activities for disaster risk reduction, preparedness, and response; (d) issuance of guidelines on DRM activities to agencies, organizations, and nongovernment organizations (NGOs), among others; (e) promotion of research and development programs; and (f) establishment and maintenance of a database on DRM. ${ }^{10}$ At the intermediate and local levels, the Disaster Management Centre has appointed district disaster management coordinators and established provincial,

9 Ministry of National Policies and Economic Affairs. 2017. Vision 2025: A Country Enriched. Colombo. page 45.

${ }^{10}$ Sri Lanka Disaster Management Act No. 13 of 2005. 


\section{Figure 4: Structure of the Sri Lanka Disaster Management System}

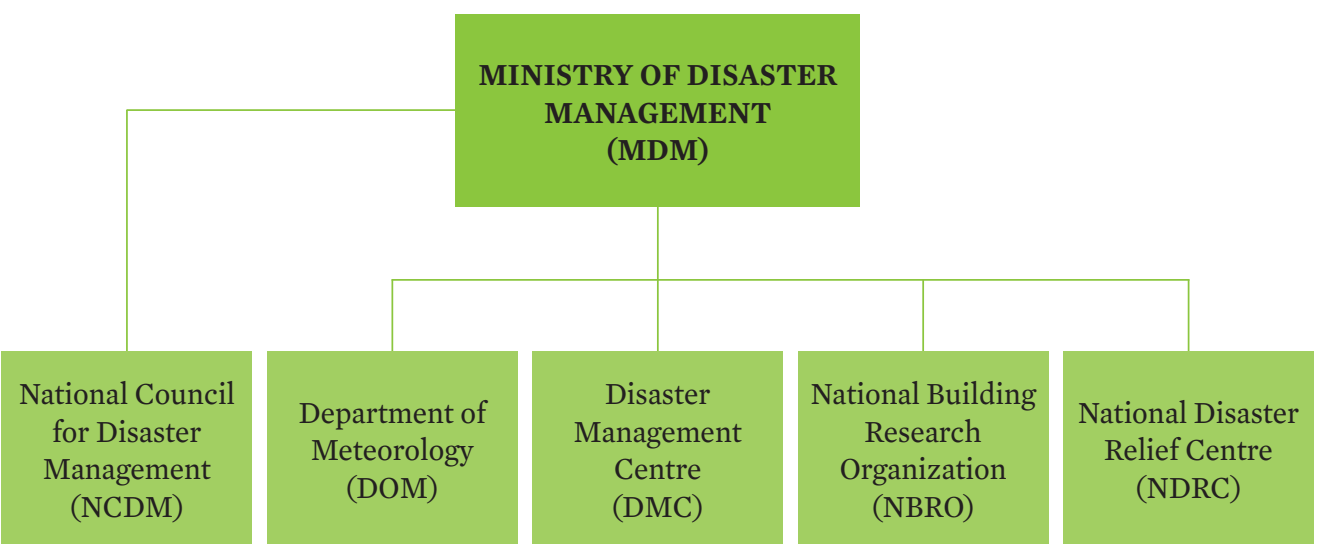

Source: Ministry of Disaster Management (2010).

district, divisional, local authority, and village-level committees to coordinate and implement disaster management activities in cooperation with line departments and relevant stakeholders.

\section{Disaster Risk Reduction and Awareness}

38. Multihazard risk and vulnerability assessments are recognized as critical in land use planning, and in the design and location of infrastructure, but enforcement remains a challenge. Accordingly, risk assessments have been made requisite in planning for the urban sector, housing development, and tourism, among others. For instance, approval permits of development activities along the coast have additional specifications to be added as an annexure, such as (i) ensuring that the proposed project is not at risk from natural hazards and would not contribute to the creation of risk, (ii) categorization of the hazard zone under which the proposed projects falls, and (iii) certification of building codes and construction practices by engineers (APDC 2011). In urban planning, integration of hazard risk information in local development plans is being undertaken to demonstrate the use of multihazard risk maps as base maps for land use zoning." The Integrated Strategic Environment Assessment, which maps all environment and disaster risk factors in an area, has also been used as a development planning tool. Enforcement of these regulations remains difficult specially in relation to the low-income population.

39. The Government of Sri Lanka is engaged in disaster risk awareness. The Ministry of Education and the National Institute of Education are mainstreaming DRM into the education curricula by conducting trainings for teachers, principals, and education management personnel; revising school curricula to include DRM components; conducting emergency exercises; piloting project-based teaching; and developing teaching and learning materials on DRM (GTZ 2007).

11 UN-HABITAT. http://www.fukuoka.unhabitat.org/projects/sri_lanka/detail20_en.html. 


\section{Disaster Risk Financing}

40. The Government of Sri Lanka has limited ex ante financing arrangements in place for post-disaster response, periodically placing significant demands on public resources. Recognizing that disasters create high economic and social burden for the government, the government seeks to strengthen public mechanisms to reduce fiscal risks following a disaster, as communicated during interviews for this report. Toward this end, it availed of a $\$ 102$ million financing agreement with the World Bank in 2014 through a credit line known as Catastrophe Deferred Drawdown Option, which provides immediate access to quick liquidity when the country declares a state of disaster. This facility had a soft disbursement trigger based on the declaration of a state of disaster and was drawn down in full by Sri Lanka in August 2016, in the aftermath of the May 2016 floods and landslides, and a proclamation of a State of Disaster by the President in accordance with Article 11 of the 2005 Disaster Management Act. This form of contingency financing can help support a timely and effective response to a disaster, reducing the need for post-disaster reallocation of development resources, and is available both from ADB and the World Bank.

\subsection{Diagnostic and Recommended Actions}

41. The National Disaster Fund should be implemented to streamline disasterrelated expenditures. Funds for disaster-related expenditure are currently allocated either through general budget formulation and, in the aftermath of some disasters, extraordinary requests to the Treasury via the National Budget Department, as noted in a World Bank report and confirmed by the work carried out in this TA:

General budget procedures apply to the post-disaster execution of all funds. However, provinces follow a distinct and separate budgeting process, which does not fully meet their needs for disaster-related expenditure. To help expedite funding and remedy shortfalls, the 2005 Disaster Management Act provides for the establishment of a National Disaster Fund, but this fund has yet to be implemented. According to the said Act, the fund is intended to consolidate external and internal funds for disasterrelated expenditure, including funds in the form of loans, donations, gifts, or grants. ${ }^{12}$

42. An effective country DRF strategy should be developed, based on detailed knowledge of the country's disaster risk and a clear statement of the related contingent liabilities of government. The Government of Sri Lanka should develop a comprehensive DRF strategy, consisting of efficient ex ante and post-financing schemes. Armed with enhanced information on the different probabilities of various types and intensities of natural hazard striking in each area of the country and probable associated damage and loss, based on disaster risk models, the government can identify the most cost-efficient basket of disaster risk financing instruments, including both ex ante and ex post mechanisms. The strategy should cover nonsovereign as well as sovereign instruments (e.g., insurance schemes for farmers and business), seeking to reduce the contingent liability on government.

\footnotetext{
${ }^{12}$ World Bank. 2016. Fiscal Disaster Risk Assessment, Options for Consideration, Sri Lanka. Colombo. page vii.
} 
43. As a basis for this disaster risk financing strategy, the government should assess the state of disaster risk assessment for the country and develop a plan of action to develop comprehensive mapping and modeling. Currently, there are no nationwide disaster risk models for Sri Lanka, hindering the development of an effective DRF strategy and the pricing of insurance, reinsurance, and capital market instruments, in turn limiting their availability. Recent analysis of historical losses by the World Bank indicates that annual expected losses from natural hazards (excluding tsunamis) for Sri Lanka's housing, roads, and relief sectors alone amount to $0.5 \%$ of GDP and $3.0 \%$ of total government expenditure over the long term, as already noted. A fuller analysis based on a comprehensive disaster risk model simulating potential hazard events and their consequences over thousands of years would enable the government to develop a comprehensive strategy. The existing hazards maps and weather data ${ }^{13}$ provide a good starting point for developing a comprehensive probabilistic disaster risk model. Such a model should be based on an open platform and should also consider the data requirements of private sector practitioners for developing risk transfer instruments.

44. Following a risk assessment of government-owned infrastructure and assets exposed to natural hazards, the development of insurance mechanisms for public assets should be considered. The Public Finance Circular No. 04/2015 dated 14 July 2015 states that the insurance of public assets should be obtained from government-owned insurance institutions directly without the services of insurance agents. To achieve this effectively, a disaster risk assessment of public assets is necessary to determine the appropriate level of coverage needed. This would be based on a comprehensive database of government assets, which itself might need to be developed. Decisions regarding risk retention in the form of deductibles and risk transfer to the market can then be undertaken in an informed manner, together with decisions on the scale and nature of disaster risk reduction measures.

45. Disaster-contingent financing could be a useful DRF instrument that the government might want to consider securing again. In view of the government's current broad economic strategy to address short-term financial imbalances and medium-term challenges, further contingent disaster loans could be a useful DRF instrument. Experience from other countries and Sri Lanka itself reveals that governments are often reluctant to declare a state of disaster, even when contingent financing is available, because of concerns about the consequences to the tourism industry and related economic and fiscal implications. Alternative triggers that are quantitative in nature could also be explored, for instance, the number of affected households from a particular disaster event.

13 The Ministry of Disaster Management, together with the National Building Research Organization, have developed hazard maps for tsunami-vulnerable areas, as well as landslides hazard and risk maps. For more details, see the Sri Lanka country diagnostic. 


\section{Diagnostic on the Current Availability and Use of Insurance, Reinsurance, and Capital Market Solutions for Disaster Risk Financing}

46. Enhanced use of disaster risk transfer instruments in Sri Lanka requires significant improvement in the associated insurance, reinsurance, and capital market enabling environment. Using the diagnostics tool presented in Section 1, several areas of improvement with respect to the use and development of disaster risk transfer instruments have been identified in the six areas of relevance for the development of disaster insurance, reinsurance, and capital market solutions (Figure 5). It should be noted that, in the case of Sri Lanka, the ideal scenario coincides to a vast extent with the achievable scenario. For this reason, the assessors decided to focus on the ideal scenario and thus formulate recommendations aimed at achieving that enabling environment.

47. The overall ratings under each of the six areas of relevance are presented in Figure 4. The factors determining these ratings and associated recommendations are discussed in further detail in this section. It should be noted that unlicensed competition is covered under the discussion on social protection, reflecting the strong focus of unlicensed competition on the low-income market in the context of Sri Lanka. Economic conditions are covered under

Figure 5: The Rating Results for Sri Lanka

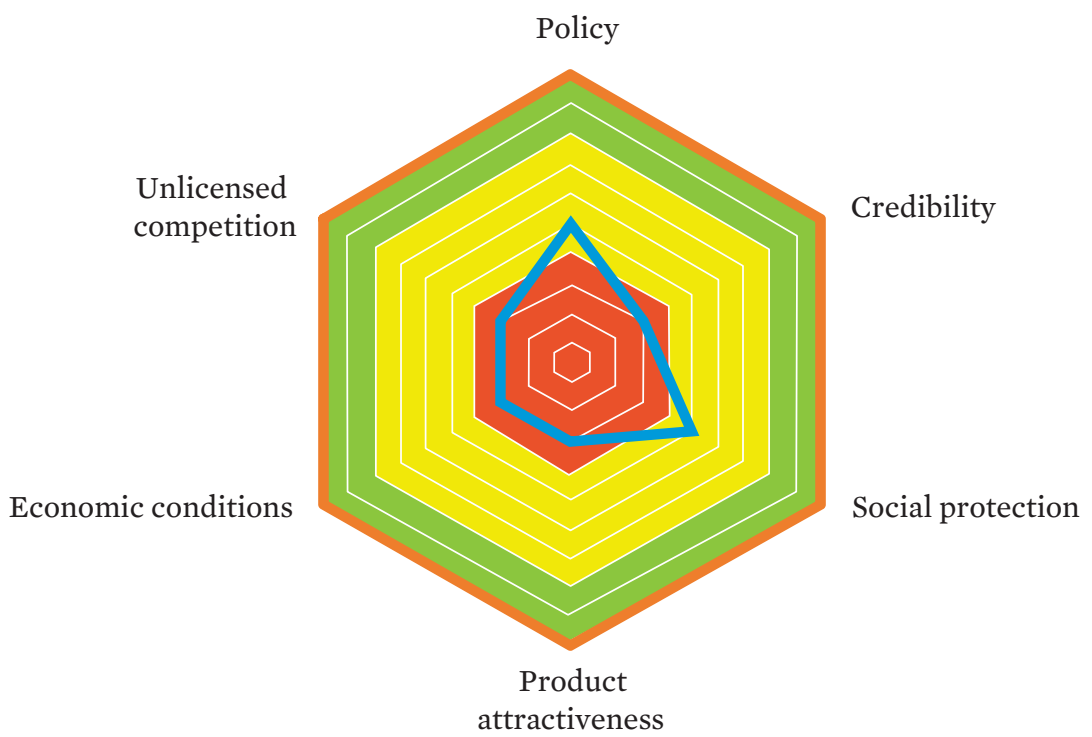

DRF IRCM existing environment

$\mathrm{DRF}=$ disaster risk financing, $\mathrm{IRCM}$ = insurance, reinsurance, and capital market. Source: Asian Development Bank. 
the discussions on policy, credibility, social protection, and product attractiveness, reflecting their cross-cutting nature.

\subsection{Government Policy}

48. Using the diagnostics tool, several areas where government policy could help nurture the growth of disaster insurance, reinsurance, and capital market solutions have been identified. Insurance schemes aligned with the government's current long-term vision should be introduced for economically-important sectors. However, it is necessary to first establish government policy that encourages and removes barriers toward the achievement of an enhanced enabling environment for the development of these risk transfer instruments.

\subsubsection{Household Disaster Risk Protection}

49. There are limited disaster risk transfer instruments currently in place in Sri Lanka and those that are in use have apparently been identified and established on an ad hoc basis. Insurance, reinsurance, and capital market solutions as tools to finance disaster response costs were used by the government for the first time in 2016. For the 2016 budget, a decision was made to set up the National Natural Disaster Insurance Scheme (NNDIS) for uninsured persons. ${ }^{14}$ The related budgetary allocation for the purchase of insurance was determined on an ad hoc basis, dependent on the availability of funding rather than on an assessment of disaster risk. Nevertheless, the benefits of this scheme have been positively experienced, with the first payouts just a few months later, as further discussed in section 3.3.2.

\subsubsection{Agricultural Sector Disaster Risk Protection}

50. Agriculture is an important sector in Sri Lanka's economy, accounting for $8 \%$ of GDP, 30\% of labor force, and 24\% of export earnings in FY 2016 (CBSL 2016a). Sri Lanka remains agrarian-based society and agriculture is inextricably linked to the culture of the people as well as remaining central to the economy, resulting in production losses. More than $75 \%$ of the population resides in rural areas whose main livelihood is agriculture. Agricultural performance has direct implications for poverty reduction. Real wage growth in the agriculture sector averaged 5.7\% per annum from 2006 to 2013, causing poverty to fall more rapidly among self-employed farmers and agricultural workers than among workers in other sectors (World Bank 2016d).

51. The Sri Lankan agriculture sector comprises several categories: (a) food crops (rice, fruits, vegetables, field crops, and spices), (b) plantation crops (tea, rubber, coconut, sugar, and oil palm), (c) floriculture and ornamental crops, (d) livestock, (e) fisheries, and (f) forestry. Key agricultural indicators for the country are indicated in Table 1. Livestock activities comprise milk and egg production and value of slaughtered animals and accounted

14 The NNDIS covers lives and properties of all uninsured households and small businesses up to SLRs2.5 million in respect of damage caused by natural perils, excluding drought, and lives for SLRs100,000 per person. Fishers registered under the Department of Fisheries are also covered to the value of SLRs1 million. Total capacity of the scheme amounts to SLRs10 billion. For 2017, the capacity has increased to SLRs15 billion and the reinsurance was not placed before the first big losses occurred. 
for $7.9 \%$ of the agricultural sector's output in $2016 .{ }^{15}$ In $2016,55 \%$ of the total land area was utilized for agriculture: $35 \%$ for paddy, $28 \%$ for plantation crops, and $37 \%$ for other crops. Paddy and tea production totaled $\$ 1.6$ billion and $\$ 1.5$ billion in value, respectively, in 2015 (CBSL 2016b), contributing $4 \%$ of GDP and $50 \%$ of agricultural production.

\section{Table 1: Key Agricultural Indicators of Sri Lanka}

\begin{tabular}{llc}
\hline Indicator & Year & Value \\
\hline Arable land (agriculture), \% of total land area & 2013 & 20.7 \\
\hline Forest area, \% of total land area & 2015 & 33.0 \\
\hline Permanent land area, \% of total land area & 2013 & 15.9 \\
\hline Arable land per capita, ha & 2013 & 0.068 \\
\hline Index of agricultural production (2004-2006=100) & 2013 & 136.1 \\
\hline Yield of rice production per ha, kg & 2014 & 3,838 \\
\hline $\begin{array}{l}\text { Per capita rice production, kg } \\
\text { ha = hectare, kg = kilogram. }\end{array}$ & 2014 & 158 \\
Source: Central Bank of Sri Lanka (2016a). & &
\end{tabular}

52. Established in 1975 under the Tea Small Holdings Development Act (No. 35 of 1975), the Tea Small Holdings Development Authority is the nodal body for several government interventions for tea plantations (e.g., relief in case of droughts, tea replanting subsidies, extension services, research, technical know-how in shed management, and data repository of smallholder farms). Tea farmers are categorized as smallholders if their plantation ownership is below 22.5 hectares. An overwhelming $99 \%$ of tea farmers are smallholders. Smallholders produced 218 million kilograms ( $\mathrm{kg}$ ) or $75 \%$ of the total 293 million $\mathrm{kg}$ country tea production in 2016. Over 500,000 smallholders are organized across 1,400 smallholder tea societies. Tea accounts for $17 \%$ of export income (Patankar and Schweizer 2016).

53. Sri Lanka is divided into three climatic zones: the wet zone in the southwestern part of the country, including the mountains; the dry zone in the western and northern regions; and the intermediate zone in between. Two monsoonal periods provide the majority of the annual rainfall to all areas: the southwest monsoon from May to August (yala), and the northeast monsoon from September to March (maha). Severe droughts occur every 3 to 4 years with those of national significance occurring every 10 years.

54. Drought, flood, and extreme wind events are the main causes of damage to agricultural crops (Wickramasinghe 2016). Agriculture's dependence on climate and rainfall, in particular, makes the sector vulnerable to extreme weather events. The seasonal distribution of loss to agricultural crops shows a cyclical distribution with two peaks. One occurs in the months of November, December, January, and February, when the retreating monsoon can result in floods but also, sometimes, due to drought. The other peak occurs in August and September mainly due to drought. The possible impacts of changes in rainfall regimes and prolonged droughts include (i) high intensity rainfall affecting harvesting and soil erosion in tea lands; and (ii) loss of agricultural productivity in rain-fed paddies, which comprise over $30 \%$ of all rice paddies, especially in the dry zone of Sri Lanka where nearly $70 \%$ of the paddies are cultivated (Ministry of Environment 2010c).

${ }^{15}$ Government of Sri Lanka, Ministry of Finance and Planning. 2017. Fiscal Management Report. p. 65. 
55. There is a clear spatial distribution of drought and flood events reflecting the climatic variations in different parts of the country (UNDP 2011). Spatial data indicate that the districts of Kurunegala and Ampara appear to have the highest loss of crop. In districts such as Colombo, Kandy, and Kalutara the loss is somewhat lower.

56. In recent years, the agriculture sector has underperformed, growing on average at $4 \%$ over the past 5 years, in part due to adverse weather. The 2012 floods resulted in a paddy production loss of 290,000 metric tons in the 2012/2013 maha season and caused damages to the livestock sector estimated at \$1.2 million. In the 2013/2014 maha season, below average rainfall during the northeast monsoon led to drought conditions damaging 83,746 hectares of paddy lands and resulting in a production loss of 280,000 metric tons, or $15 \%$ of forecasted production. As a consequence of the severe drought, over 728,000 people were estimated to be food insecure. In fiscal year 2016, however, the sector recorded a negative growth of $-4.2 \%$ due to the floods in May, followed by the drought beginning in September which significantly reduced paddy cultivation (ADB 2017a). The drought and floods disrupted two rice cultivation cycles, reducing domestic rice production in 2017 to its lowest level in the last 10 years and to only 7 months of national consumption, according to government estimates (IMF 2018). Agricultural export earnings fell by 6.3\% in 2016, mostly due to lower exports of tea and spices (CBSL 2016a, p. 153). Tea contributed 55\% of agricultural exports in 2016; tea exports were recorded at $\$ 1.27$ billion, the lowest level in 7 years as tea production declined in part due to the adverse weather conditions. Key agricultural loss statistics from recent major disasters affecting Sri Lanka are indicated in Table 2.

Table 2: Damage and Loss in the Agriculltural Sector

\begin{tabular}{|c|c|c|c|c|c|c|}
\hline $\begin{array}{l}\text { Disaster } \\
\text { Event }\end{array}$ & Year & $\begin{array}{c}\text { Crop Area } \\
\text { Damage } \\
\text { (hectares) }\end{array}$ & $\begin{array}{c}\text { Crop } \\
\text { Losses } \\
\text { (\$ billion) }\end{array}$ & $\begin{array}{l}\text { Livestock } \\
\text { Losses } \\
\text { (\$ billion) }\end{array}$ & $\begin{array}{c}\text { Total } \\
\text { Agricultural } \\
\text { Losses } \\
\text { (\$ billion) }\end{array}$ & $\%$ of GDP \\
\hline Drought & 2014 & 85,000 & 0.05 & 0.10 & 0.15 & $0.20 \%$ \\
\hline Floods & May 2016 & 9,771 & 0.01 & Insignificant & 0.01 & Insignificant \\
\hline Drought & September 2016 & $1,500,000$ & 0.20 & Not quantified & 0.20 & $0.25 \%$ \\
\hline
\end{tabular}

GDP = gross domestic product.

Sources: Ministry of Economic Development, Ministry of Disaster Management, and World Food Programme (2014).

57. Agricultural insurance has an important role to play in managing disaster risk, in particular pertaining to extreme weather events, at different levels of aggregation. This includes insurance at the individual farmer- or micro-level, to smooth consumption and offer protection, to incomes in the event of major weather shocks and plant disease outbreaks; at the meso-level as a business interruption cover to protect agriculture loan portfolios of financial institutions and input suppliers; and, finally, at the macro- or government-level to support relief and early recovery for vulnerable groups in the aftermath of disasters. Agricultural insurance also increases access to farm credit by reducing associated risks of lending and encourages investment in related technological tools and modernization necessary for its implementation, e.g., weather stations, satellite monitoring. The appendix outlines the key learnings from international experience on agricultural insurance. 
58. The Government of Sri Lanka has placed significant focus on promoting agricultural insurance as a tool to protect vulnerable farmers, enhance food security, and channel agricultural credit. The government's policy on agricultural insurance (i.e., crop insurance and livestock insurance) can be traced to the 1958 pilot crop insurance scheme which covered approximately 11,600 hectares of paddy in five districts. By 1974, nearly $16 \%$ of the total area cultivated with paddy was covered by insurance. The Crop Insurance Board in Sri Lanka was established in 1974 under the Parliamentary Act No. 27 of 1973 to operate a comprehensive crop insurance scheme for rice, other field crops, and livestock.

59. In line with the government's budget proposal, a new crop insurance scheme was established in 2013. Farmers who receive subsidized fertilizer under the "Kethata Aruna Pohora Diriya" program are compulsorily covered by the crop insurance scheme to compensate for crop damages caused by droughts, flood, and wild elephant attacks. The scheme operates per Circular No. BD/EE/118/01/BP/2013 dated 21 June 2013 issued by the Ministry of Finance and Planning. This scheme was managed by the National Insurance Trust Fund (NITF) (section 3.2.2) until it was transferred to the Agricultural and Agrarian Insurance Board (AAIB) at the end of 2014, as per the Ministry's circular no. DFD/Circular/2014-03. AAIB is presently responsible for premium collection, claims handling, and overall management of the government's crop insurance scheme. The scheme charges a small premium (relative to the risk underwritten) of $1.5 \%$ of the sum insured to the farmers who receives subsidized fertilizer. The premium rate is uniform across crops and geography.

60. The crop insurance levy supports the AAIB insurance products. To fund the underwriting losses that AAIB may incur under the government's crop insurance scheme, all banks and financial institutions (including microfinance companies) are required to contribute $1 \%$ of net profits to NITF as a crop insurance levy. ${ }^{16}$ In 2016 , the government widened the use of the crop insurance levy to pay claims under the National Loan Protection Scheme (para. 61). Figure 6 displays the working of the crop insurance levy. As per NITF's audited financial statements for FY 2014, the crop insurance levy fund is worth SLRs1.2 billion. From inception to end-2016, NITF has received SLRs5.1 billion toward the crop insurance levy and paid out SLRs3.9 billion for insurance claims and other damages. ${ }^{17}$ In effect, the NITF bears claims beyond the premium collected by AAIB under the crop insurance scheme.

61. In 2016, the government introduced the National Loan Protection Scheme to provide further relief to farmers who could not repay bank loans due to damage to their paddy crops. Under the National Loan Protection Scheme, NITF will compensate the relevant bank or financial institution from the crop insurance levy if a farmer defaults on paddy cultivation loan due to either drought, flood, or elephant attack, subject to a ceiling of SLRs10,000 per acre (SLRs22,222 per hectare). The government has estimated that SLRs500 million will have to be paid to banks in lieu of the loan obtained by the farmers during the 2016/2017 maha season (Department of Government Information 2017a). However, it is noteworthy that the sum insured on AAIB's insurance scheme of SLRs10,000 per acre is only approximately a third of the cultivation cost, so, in practice, loans are not adequately insured. On the other hand, some private sector insurers cover production costs and part of profits.

${ }^{16}$ Sri Lanka Finance Act No. 12 of 2013, Sec. 14.

17 Government of Sri Lanka, Department of Government Information. 2017. News Release. 7 May. 


\section{Figure 6: Flow of Crop Insurance Levy}

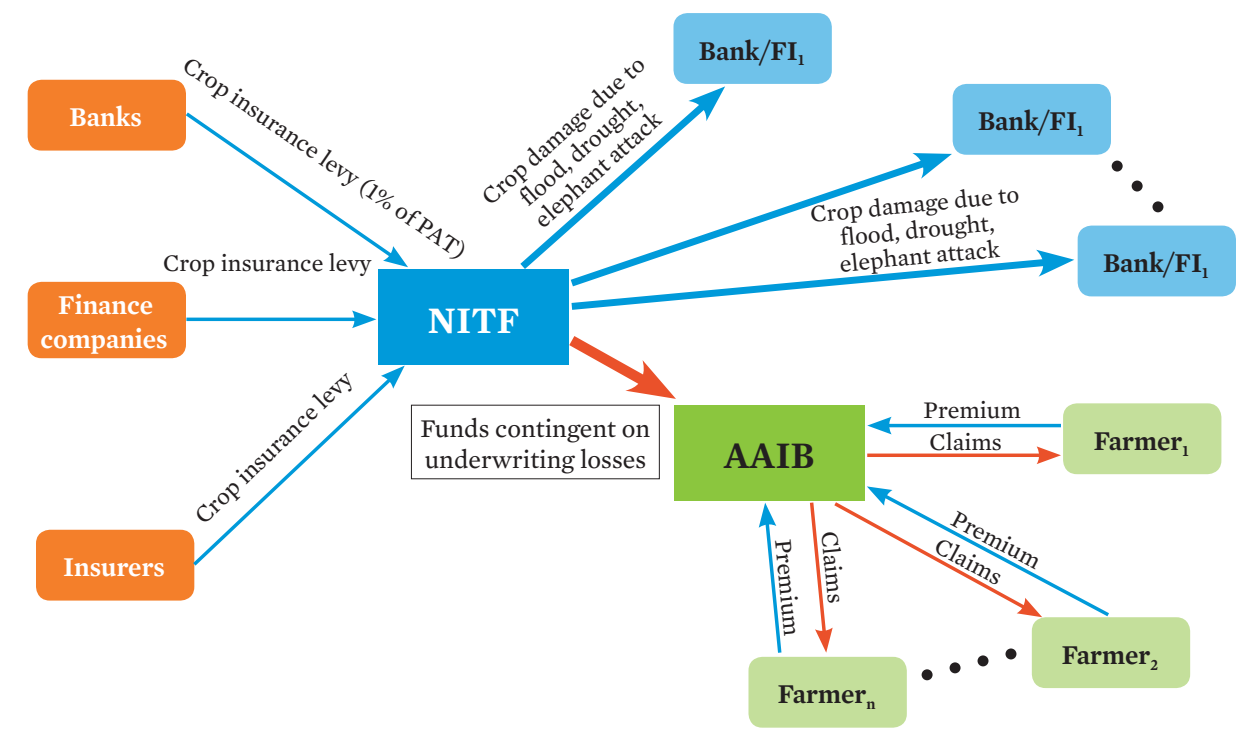

AAIB = Agricultural and Agrarian Insurance Board, FI = financial intermediary, NITF = National Insurance Trust Fund, PAT $=$ Profit after Tax.

Source: Asian Development Bank.

62. The government also promotes interest subvention and compulsory insurance on farm credit. Insurance products are often compulsory for farmers who seek institutional credit for crop cultivation and the purchase of livestock. This has helped to increase the penetration of scheme-based insurance products. Agriculture sector credit in Sri Lanka is currently available through licensed commercial banks, licensed specialized banks, registered finance companies, Samurdhi Bank Societies, ${ }^{18}$ cooperatives, and microfinance institutions. The public sector banks (Bank of Ceylon and People's Bank) also require their cultivation loan borrowers to purchase compulsorily insurance up to the loan amount. Simultaneously, the government, through the Central Bank of Sri Lanka, provides an interest rate subvention of approximately $7 \%-8 \%$ per annum to the banks for cultivation loans. The government policy of an interest rate subvention thus supplements the crop insurance business.

\subsubsection{Diagnostic and Recommended Actions}

63. A declared government policy on the use of risk transfer instruments for DRF purposes is recommended. There is no government policy with respect to insurance, reinsurance, and capital market solutions as a form of DRF. Maintaining the continuity of programs such as NNDIS (section 3.3.2) would benefit the government budgeting process by helping to smooth the cost of government disaster response spending over time in return for annual premium payments. The international reinsurance and other financial markets

18 The Samurdhi (or Prosperity) Programme was launched by the Government of Sri Lanka in 1995 with the main goal of reducing poverty through development based on public participation. A savings and credit program operates through the Samurdhi Bank Societies. 
would provide competitive rates, terms, and conditions for a multiyear program, resulting in certainty on the costs and availability of protection over several years.

64. Agricultural insurance needs to be supported by initiatives that holistically integrate the existing crop insurance levy's cumulated fund with the delivery of subsidies. The crop insurance levy is presently used as a contingent fund available to AAIB to meet its underwriting losses from its crop insurance business. AAIB's crop insurance business is also closely linked to the fertilizer subsidy; the insurance levy, set at SLRs150 per acre (SLRs333 per hectare), is collected from farmers when they pay for subsidized fertilizer. Since 2016, the government has moved away from the subsidized fertilizer distribution to the issuance of coupons for a flat SLRs25,000 (including crop insurance) which farmers can use to buy fertilizer from the private market. This design has a few advantages-it avoids the costs of collecting the insurance levy separately, and also ensures mandatory coverage of poor farmers. On the other hand, this arrangement risks crowding out the private insurance industry and discourages the development of new crop insurance products. In view of this, the policy on agricultural subsidy and the crop insurance levy needs to be examined together. The government and policy makers should consider the following:

(i) Should the farmer's coupon credit continue to be linked to the crop insurance levy?

(ii) Does the crop insurance levy distort the agricultural insurance market by providing contingent funds only to AAIB?

(iii) How could the insurance industry be incentivized to participate in crop insurance and deepen the market?

(iv) How could the crop insurance levy and subsidy work together to reduce market distortion?

(v) In view of the relative advantage to NITF (as a reinsurer, as well as a direct insurer) and AAIB (unregulated) in crop insurance, are other insurers incentivized to underwrite agricultural risks?

(vi) Could the crop insurance levy be otherwise used to overcome market inefficiencies such as

(a) by financing crop information systems on area yield and other agricultural information?

(b) by financing improvements to infrastructure and technology support for ratemaking, e.g., weather stations, satellite networks?

(c) by financing insurance literacy campaigns for farmers?

(d) by financing enhanced technical capacity on early warning systems and claims assessment?

(vii) Could the government contribute more to this important aspect of disaster resilience of the agricultural sector?

65. The crop insurance levy strategy should be revisited. The crop insurance levy collections should be put to smarter use to achieve a solvent crop insurance market that attracts high interest from the private insurance industry. It is recommended that the crop insurance levy program is treated as a separate focus area (within NITF) so that the funds are channeled to targeted projects that build medium- to long-term public goods-e.g., meteorological infrastructure (section 3.2.3) and services around the design of microlevel crop insurance, distribution strengthening by establishing linkages with the agricultural extension services, and establishment of a technological platform for the coupon system for subsidy to farmers. The program could also provide a facility to pool funds from donors for meso-level insurance, e.g., an insurance program highly correlated with the crop loan portfolio's performance. 
66. Insurance skill sets and capacity need to be developed around the country's central crops: rice and tea. The high variability in climatic conditions and agricultural output, and the challenges of natural hazards demonstrate the need to protect key food and export crops. Indeed, it is recommended that rice and tea be the central crops around which insurance capacity is developed. Rice and tea production of $\$ 1.6$ billion and $\$ 1.5$ billion, respectively, in 2015 contributed approximately $4 \%$ of GDP and $50 \%$ of agricultural production (CBSL 2016b). Underwriting losses have historically been higher for rice as compared with tea, reflecting the fact that rice forms a major part of the $24 \%$ area under rain-fed agriculture. Currently, the private sector underwrites crop insurance on a parametric (mostly through Sanasa Insurance Company) and indemnity (mostly through Ceylinco General Insurance) basis (section 3.3.3). Greater focus on the development of capacity (e.g., pricing, product design, technology for underwriting and claims settlement) and information infrastructure (e.g., information on area yield, weather data) around rice and tea insurance would increase penetration, aid pricing of premium, provide scope for customized products, and reduce the cost of cover. With greater support in the form of capacity and information infrastructure, as outlined above, the insurance market could explore the provision of insurance for tea planters, contract farmers, and agricultural supply chain managers.

67. Provision of insurance for smallholder tea growers needs to be explored. Smallholder tea growers contribute about $75 \%$ of Sri Lanka's tea production. However, they remain vulnerable to natural hazards. The Tea Smallholders' Association of Sri Lanka is an important stakeholder which could be used to distribute insurance and underwrite many small tea farms on a collective basis. It would be worth exploring area yield index insurance products for smallholder tea growers in partnership with the Tea Smallholders' Association of Sri Lanka and private sector insurers currently active in agricultural insurance. This initiative can be bundled with institutions financing smallholder tea growers.

\subsection{Credibility of the Private Sector Offering Risk Transfer Solutions}

68. The growth trend shown by the insurance sector since 2012 continues. ${ }^{19}$ The Sri Lankan insurance industry has shown a combined growth of $16.27 \%$ year-over-year in 2016, with life achieving a gross written premium of SLRs63.495 billion (18.26\% growth) and non-life achieving a gross written premium of SLRs79.474 billion (14.73\% growth). The total industry gross written premium stood at SLRs142.97 billion as of the end of 2016. Although low compared to other markets, particularly in Asia, the insurance penetration as of year-end 2016 stood at $1.21 \%$ (life $0.54 \%$ and non-life $0.67 \%$ ). Total assets of the insurance industry (after eliminating inter segment transactions), comprising the assets belonging to long term and general insurers and the national reinsurer, NITF, amounted to SLRs527,228 million as of 31 December 2016. This was an annual increase of $12.97 \%$ (Table 3).

69. Voluntary agriculture insurance remains low, but the penetration is increasing. In 2016, the two main providers of agricultural insurance, Ceylinco General Insurance and Sanasa Insurance Company, reported agricultural insurance premiums of

19 Per the latest data available in the IBSL, now known as Insurance Regulatory Commission of Sri Lanka (IRCSL), webpage. http://www.ibsl.gov.lk/images/IBSL-AR\%202016-Inner-21-59.pdf. 


\section{Table 3: Total Gross Premiums Recorded \\ by the Insurance Industry, 2012-2016 \\ (in SLRs billion)}

\begin{tabular}{|lrrrrrrrrr|} 
Class & $\mathbf{2 0 1 2}$ & $\mathbf{2 0 1 3}$ & Growth & $\mathbf{2 0 1 4}$ & Growth & $\mathbf{2 0 1 5}$ & Growth & $\mathbf{2 0 1 6}$ & Growth \\
Life & 37.48 & 41.68 & $11.21 \%$ & 44.60 & $7.01 \%$ & 53.69 & $20.38 \%$ & 63.50 & $18.27 \%$ \\
Non-Life & 53.21 & 58.28 & $9.53 \%$ & 61.20 & $5.01 \%$ & 69.27 & $13.19 \%$ & 79.47 & $14.72 \%$ \\
$\begin{array}{l}\text { Total } \\
\text { (industry) }\end{array}$ & $\mathbf{9 0 . 6 9}$ & $\mathbf{9 9 . 9 6}$ & $\mathbf{1 0 . 2 2 \%}$ & $\mathbf{1 0 5 . 8 0}$ & $\mathbf{5 . 8 4 \%}$ & $\mathbf{1 2 2 . 9 6}$ & $\mathbf{1 6 . 2 2 \%}$ & $\mathbf{1 4 2 . 9 7}$ & $\mathbf{1 6 . 2 7 \%}$ \\
\hline
\end{tabular}

Source: Insurance Board of Sri Lanka (2017).

SLRs200 million and SLRs76 million, respectively. Both companies recorded healthy renewal rates of approximately $80 \%$. Loss ratios were manageable, with higher loss proportions in rice (a range from $70 \%$ to $100 \%$ loss ratio), livestock (nearly 100\%), and lower losses in plantation crops (a range from $40 \%$ to $70 \%$ loss ratio). Overall, both the public and private sector agricultural insurance underwriters have gathered some experience over the past few years. With greater support, the agricultural insurance underwriters can improve market presence and deliver more client value.

\subsubsection{Regulation and Supervision}

\section{The Insurance Regulatory Commission of Sri Lanka}

70. The Insurance Regulatory Commission of Sri Lanka (IRCSL) oversees the supervision and regulation of the insurance sector. The IRCSL was established under the Regulation of Insurance Industry Act No. 43 of 2000 with the sole purpose of regulating and supervising insurance companies, insurance brokers, insurance agents, and loss adjusters. The object and responsibility of the IRCSL is to ensure that insurance business in Sri Lanka is transacted with integrity and in a professional and prudent manner with a view to safeguarding the interests of policyholders, and potential policyholders. ${ }^{20}$ The Act was amended by the Regulation of Insurance Industry Act Nos. 27 of 2007, 03 of 2011, and 27 of 2017. The stated vision of IRCSL is "to be the benchmark insurance regulator in Asia" and its stated mission is "to protect policyholder's interest whilst regulating, supervising and facilitating the development of the insurance industry" (Insurance Board of Sri Lanka 2012). As per the IRCSL Annual Report of 2015, there are 43 staff members attached to IRCSL.

71. The powers, duties, and functions of the IRCSL include the following:

(i) Register as insurers persons carrying on insurance business in Sri Lanka.

(ii) Register persons as insurance brokers.

(iii) Advise the Government on the development and regulation of the insurance industry.

(iv) Implement the policies and programs of the Government with respect to the insurance industry.

(v) Carry out such other acts as may be necessary for the due exercise, discharge and performance of its powers, duties and functions under this act. ${ }^{21}$

${ }^{20}$ Insurance Regulatory Commission of Sri Lanka. http://ircsl.gov.lk/about-ibsl.html.

${ }^{21}$ Footnote 20. 
72. New regulations requiring the segregation of composite insurers and their listing, as well as the introduction of risk-based capital, have enriched the insurance sector. With the segregation of composite insurers, the sector has gained focus on the non-life and life insurance businesses. Also, the comingling of assets and the cross-subsiding between life and non-life business that was previously allowed in the past is no longer possible. Riskbased capital requirements are currently being introduced. Accordingly, every insurer is required to maintain a capital adequacy ratio of a minimum of $120 \%$, and a total available capital of SLRs500 million. The rules also specify guidelines for admissible assets, asset limits, valuation of assets and liabilities, and determination of risk capital factors for each class of assets and liabilities. IRCSL regulation also requires insurance companies to be listed by 2016 , but some have been allowed to delay until end-2017.

\section{The Securities and Exchange Commission}

73. The Securities and Exchange Commission of Sri Lanka (SEC) is responsible for the regulation and supervision of the capital markets. The SEC was established in pursuance of the Securities and Exchange Commission of Sri Lanka Act, No. 36 of 1987, as amended by Act No. 26 of 1991, Act No. 18 of 2003, and Act No. 47 of 2009 with the mission to promote, develop, and maintain a capital market that is fair, efficient, orderly, and transparent. The SEC objectives are as follows:

(i) the creation and maintenance of a market in which securities can be issued and traded in an orderly and fair manner;

(ii) the protection of the interest of investors;

(iii) the operation of a Compensation Fund to protect investors from financial loss arising as a result of any licensed stock broker or licensed stock dealer being found incapable of meeting his contractual obligations; and

(iv) the regulation of the securities market and to ensure that professional standards are maintained in such market. ${ }^{22}$

74. Over time, its powers, duties, and functions have expanded, currently including the following:

(i) to grant a license to a corporate body to operate as a stock exchange, to any person to operate as a stock broker or a stock dealer and to a managing company to operate a unit trust. SEC should also ensure the proper conduct of their businesses;

(ii) ... to grant a certificate of registration to any person to carry on business as a market intermediary and to ensure the proper conduct of such business;

(iii) ... to advise the government on the development of the securities market;

(iv) ... to inquire and conduct investigations into any activity of a licensed stock exchange, a licensed stock broker or licensed stock dealer, a licensed managing company or a trustee of a unit trust, a registered market intermediary or any listed public company;

(v) ... to implement the policies and programs of the Government with respect to the market in securities;

(vi) ... to request the Registrar of Companies, in the exercise of the powers conferred on it by section 227 of the Companies Act, No. 17 of 1982, to call upon a private limited liability company to become a public limited company;

\footnotetext{
22 Securities and Exchange Commission of Sri Lanka. Objective. http://www.sec.gov.lk/?page_id=1434.
} 
(vii) ... to conduct investigations into any alleged violation or contravention of the provisions of this Act or any rule or regulation made there under by any person;

(viii) ... to do all such other acts as may be incidental or conducive to, the attainment of the objects of the Commission or the exercise of its powers under this Act. ${ }^{23}$

75. The Securities and Exchange Commission (SEC) consists of 10 non-executive members and operates through a Secretariat headed by a Director General. More specifically,

The non-executive members constitute the policy-making arm of the SEC. Six members are appointed to the Commission by the Minister taking into consideration the wide experience and vast knowledge they possess in legal, financial, business and administrative matters. The seventh appointed member is the Deputy Governor of the Central Bank of Sri Lanka. The remaining three are members by virtue of the offices they hold, comprising the Deputy Secretary to the Treasury, the Registrar of Companies, and the President of the Institute of Chartered Accountants of Sri Lanka. The Minister nominates one member from amongst the members of the Commission to be the Chairman of the Commission. The appointed members hold office for a term of three years and are eligible for reappointment. ${ }^{24}$

\section{The Consumer Protection Infrastructure}

76. The Consumer Affairs Authority. The Consumer Affairs Authority is the apex government organization mandated to protect consumers' (including insurance consumers) interests and ensure fair market competition in Sri Lanka. It was established under the Consumer Affairs Authority Act No. 09 of $2003,{ }^{25}$ which lays down the legal provisions empowering the Consumer Affairs Authority to safeguard the interests of consumers ${ }^{26}$ while maintaining effective competition among suppliers of goods and services. ${ }^{27}$ The agency comes under the purview of the Ministry of Cooperatives and Internal Trade.

77. The Ombudsman. The Ombudsman's office in Sri Lanka was set up in February 2005. The objective of the Sri Lanka Insurance Ombudsman scheme is

the satisfactory settlement of complaints/disputes that policy holders of insurance companies (the insured) may have against the company that sold them the insurance

${ }^{23}$ Securities and Exchange Commission of Sri Lanka. Power, Duties and Functions. http://www.sec.gov.lk/?page_ $\mathrm{id}=1434$.

${ }^{24}$ Securities and Exchange Commission of Sri Lanka. Members of the Commission and Its Composition. http:// www.sec.gov.lk/?page_id=137.

25 The Act repealed the Consumer Protection Act No. 01 of 1979, Fair Trading Commission Act No. 01 of 1987, and Control of Prices Act (Cap 173).

${ }^{26}$ Negotiations with the insurer concerned. As an initial step in dispute resolution in the event of a disputed claim, the claimant could appeal against the decision with the insurer concerned. The claimant's efforts could be supported by professionals at the discussions.

Lodge a complaint with the Insurance Ombudsman. A complaint is officially lodged in writing with the Insurance Ombudsman. The ombudsman would assess the case and call for information, reports and other relevant documents from the insurance company. Based on the information gathered he could deliver his opinion or in the event he cannot arrive at a decision, a discussion is arranged between the aggrieved parties at his office for a settlement of the dispute.

Appeal to Insurance Regulatory Commission of Sri Lanka. The claimant, if he/she is unhappy with the outcome of the aforementioned dispute resolutions, could appeal to the IRCSL for a further review.

${ }^{27}$ Consumer Affairs Authority. Overview. http://www.caa.gov.lk/web/index.php?option=com_content\&view=articl e\&id=78\&Itemid=507\&lang=en. 
policy (the insurer)... Any award/decision given by the Insurance Ombudsman up to a sum of SLRs1,000,000 after inquiry into a complaint made by the insured against the insurer is binding on the insurer and the insurer is expected to honor such award (or) decision. The method by which complaints can be made to the Ombudsman, and the procedure for the settlement of disputes, etc., is simple. The procedure has also been publicized and is available (online). ${ }^{28}$

\subsubsection{The Insurance Providers}

78. As per the Annual Statistical Report published by IRCSL, the insurance sector consists of 15 non-life and 15 life insurers (Insurance Board of Sri Lanka 2017). Three insurance companies (MBSL Insurance, Sanasa Insurance, and Sri Lanka Insurance Corporation Limited) have still to segregate their business to life and non-life. Other key insurance providers are the National Insurance Trust Fund Board (NITF), Sri Lanka Insurance Corporation Limited (SLIC), and the Agricultural and Agrarian Insurance Board (AAIB). The AAIB is not regulated by the IRCSL.

\section{The National Insurance Trust Fund Board}

79. The National Insurance Trust Fund Board (NITF), the only reinsurer in Sri Lanka, is of critical importance in supporting the government's risk transfer activities. It was established in 2006 by the NITF Act and is under the Ministry of Youth Affairs, Project Management and Southern Development. It is $100 \%$ government-owned.

80. By law, NITF enjoys a mandatory $30 \%$ cession from all reinsured non-life insurance business. Reinsurance premiums accounted for $22 \%$ of NITF's gross written premiums in 2015. Other businesses include the original business assigned to NITF when it was founded. These include Agrahara, the largest health insurance scheme in the country, which covers all state-sector employees and their families (about 2.5 million individuals). Since 2007, NITF has also managed the Strike, Riot, Civil Commotion and Terrorism Fund (SRCCT), which covers all non-life policies and has accumulated significant funds due to low or no claims in recent years. NITF also has an agricultural loan insurance scheme covering loans and advances extended to farmers by banks and lending institutions. To fund this scheme, the government requires all banks and financial institutions to channel $1 \%$ of their net profits to NITF through the crop insurance levy (section 3.1.2).

81. Until the end of 2014, NITF also managed the crop insurance scheme, which was established by the government budget in 2013 to mitigate damage to crops due to drought, floods, and wild elephant attacks. However, since 2015, this scheme has been managed by Agricultural and Agrarian Insurance Board (AAIB), which carries out claims handling, although some funding for this is still generated through the crop insurance levy.

82. In April 2016, the government obtained its first disaster cover (the NNDIS) from NITF, insuring losses triggered by natural hazards up to SLRs10 billion (section 3.3.2).

\footnotetext{
${ }^{28}$ The Sri Lanka Insurance Ombudsman. 2018. About the Ombudsman Scheme. http://insuranceombudsman.lk/ ombudsman-scheme/.
} 
83. NITF has been extremely profitable and enjoys the country credit rating (Fitch Ratings 2017). ${ }^{29}$ It achieved a pre-tax return on assets (ROA) of $39 \%$ in 2015 , mainly due to a low combined ratio of $54 \%$ compared to an industry average of $99 \%$. NITF benefits from a low expense ratio-14\% in 2015 , compared to an industry average of $36 \%$. NITF was the fourth largest contributor to the government consolidated fund in 2015. Although NITF does not enjoy an explicit government guarantee, the market considers NITF to have a strong implicit government guarantee and, as such, the recent credit rating issued by Fitch reflects the country rate of $\mathrm{B}+/$ Negative.

84. However, NITF retained all assumed risk on its own account until 2015. Given NITF's pivotal importance for the solvency of the insurance industry, operating without adequate retrocession at any time exposes the country to systemic risk of the collapse of the insurance sector. The procurement process of retrocessions should be enhanced.

\section{Sri Lanka Insurance Corporation Limited (SLIC)}

85. Together with NITF, SLIC has a dominant market position and enjoys a monopoly of public-sector insurance. SLIC was established under the Insurance Corporation Act of 1961 through the nationalization of the insurance industry that was previously run by many local and foreign private companies. SLIC is the oldest operating insurer in Sri Lanka with an extensive network of 125 branches throughout the country. SLIC has the highest market share in the non-life business and the second-highest share in life, as measured by gross written premiums. The company's asset base of SLRs167 billion at the end of 2015 accounted for $36 \%$ of the insurance sector's assets. Its current Fitch rating is B+ (Fitch Ratings 2017). ${ }^{30}$ The company is government-owned, but, notwithstanding regulatory requirements to segregate life from non-life business, it continues to operate as a composite insurer and has not been listed.

86. SLIC is well capitalized, but the investment assets are exposed to high volatility. Current regulatory risk-based capital ratios at end-September 2016 were $410 \%$ for life and $211 \%$ for non-life. These ratios are well above the regulatory requirement of $120 \%$. However, SLIC's total investment in equities (including non-core subsidiaries) was about $96 \%$ of shareholders' equity at end-2015 (99\% at the end of 2014). The exposure to market risk is thus high and creates volatility in the solvency ratio. SLIC liquidity is high, with a minimum of SLRs1 billion of its life funds held in liquid securities (short-term government debt and cash) and $27 \%$ of invested assets held in government securities.

87. The reinsurance program against disasters triggered by natural hazards was tested during the 2016 floods, performing well (section 3.3.2). The combined ratio for the non-life business deteriorated to $108 \%$ in the first half of 2016 (compared to $94 \%$ in 2015) due to higher claims stemming from a severe tropical storm in May 2016 that caused flooding and landslides in several parts of the country. Gross claims rose to 63\% to SLRs5.5 billion in the first half of the year (compared to SLRs3.4 billion in the first half of 2015), but net claims rose

${ }^{29}$ Reuters. 2017. Fitch Affirms National Insurance Trust Fund at AA(lka). 30 October. https://www.reuters. com/article/fitch-affirms-national-insurance-trust-f/fitch-affirms-national-insurance-trust-fund-at-aaidUSFit2Cjlbv.

${ }^{30}$ Reuters. 2017. Fitch Upgrades Sri Lanka Insurance Corp's National Ratings. 11 August. https://www.reuters.com/ article/fitch-upgrades-sri-lanka-insurance-corps-idUSFit51bBRN. 
by only $32 \%$ due to recoveries from reinsurance. In 2015, most of SLIC's non-state-owned reinsurers were rated 'BBB+' and above but $30 \%$ of its business is reinsured with NITF.

\section{The Agricultural and Agrarian Insurance Board (AAIB)}

88. The Agricultural and Agrarian Insurance Board (AAIB) was founded under Act No. 20 of 1999. AAIB is the main agricultural insurer in Sri Lanka. It has a network of 26 district offices and 550 individual service centers serving about 15,000 villages. AAIB was created with the following two objectives enshrined under the Agricultural and Agrarian Insurance Board Act, 1999:

(i) "To launch an insurance scheme and a social security benefit scheme covering the farming and the fisheries sectors and providing old age benefits through principal activities such as granting pensions and social security benefits for the farmers and the fishermen.

(ii) To achieve the desired goal of bettering farms and farmers' lives, ensuring their effective participation in the overall national production and the enhancement of their lifestyles."31

89. AAIB is not regulated by IRCSL, the insurance regulator, in line with Section 12(3) of the Regulation of Insurance Industry Act No. 43 of 2000.

90. AAIB supports the objectives of the government to transfer farmers' risk to an insurer. Presently, the AAIB has a large suite of indemnity-based "compulsory crop insurance schemes" for farmers receiving subsidized fertilizer (section 3.1.2). The crop insurance products cover the cultivation of a range of crops including paddy, maize, gram, sugarcane, big onion, coconut, potato, chili, vegetables, bananas, and other fruit. It also offers other products like accident insurance for farmers and agricultural equipment insurance.

91. While AAIB manages its agricultural insurance portfolio on insurance principles, it also performs other significant roles. The AAIB also manages government grants for allied activities. For its agricultural insurance business, AAIB has an initial capital from the government of SLRs50 million (AAIB 2014).

92. More importantly, it performs a significant role as pension provider to farmers and fishers. About 965,000 farmers and 68,000 fishers are covered under AAIB's Farmers' and Fishers' Pension Scheme. AAIB assumed operational responsibilities for the pension scheme from 2014 after SLRs1.9 billion was allocated from the national budget and the administration responsibilities entrusted with AAIB. In 2014, SLRs2.1 billion and SLRs0.42 billion were paid as pension to about 124,000 farmers and 3,000 fishers respectively. Farmers older than 63 years receive a pension along a scale starting at SLRs1,000 per month, and increasing to SLRs5,000 per month for those older. A gratuity is also paid to the families of deceased scheme members i.e., farmers and fishers.

93. The AAIB financial statements carry a liability of SLRs53 billion toward the pension schemes. A pension liability of SLRs5.5 billion, last determined in 2007, was carried over at that value in 2014 (AAIB 2014). The farmers' and fishers' pension scheme liabilities need to be actuarially valued at the current date, recognized in the financial statements,

${ }^{31}$ AAIB. 1999. Agricultural and Agrarian Insurance Board. Act No. 20 of 1999. Colombo. Section 7. 
and provided for in the national budget. Sensitivities of the liability to various parameters, e.g., longevity and interest rate, need to be understood. The present fiscal obligation of the government remains unascertained as the "Pay As You Go" farmers' and fishers' pension liabilities are not evaluated.

\subsubsection{Insurance Support Services}

\section{Credit Rating Agencies}

94. The following credit rating agencies have been approved by the Securities and Exchange Commission of Sri Lanka: Fitch Ratings Lanka Limited, Lanka Orix Factors Limited, and ICRA Lanka Limited.

\section{Actuarial and Accounting Profession}

95. The Actuarial Association of Sri Lanka (AASL) is the professional body representing actuaries, associates, and actuarial students in Sri Lanka. Currently, it is an associated member of the International Actuarial Association and applied for full membership at the end of 2016. The actuarial profession in Sri Lanka is not well developed, with less than 10 actuaries working in the country. Actuarial support from neighboring countries is widely used by the insurance sector. The new regulations will increase the demand for actuaries.

96. The large international accounting firms operate together with several national firms in the market. There appears to be a sufficient supply of auditors and accountants in the market. However, the quality of auditing varies, the professional body Chartered Accountants of Sri Lanka supervises accountants and auditors. Fitch and Moody's provide ratings to the insurance sector and are supervised by the SEC.

\section{Meteorological Services}

97. The Department of Meteorology (DoM) has divided the country into 48 agroclimatic zones-perhaps the highest granularity in the world when compared with countries of a similar size. The DoM operates approximately 400 weather stations across the country, of which only 38 are automatic weather stations. The remaining majority of weather stations are manually operated. Uninterrupted data sets are available over the past 30 years for precipitation, temperature (maximum and minimum), humidity, and windspeed. The country has long records of meteorological observations (e.g., rainfall) at a large number of stations, providing a dense spatial coverage for an island of roughly $225 \mathrm{~km}$ by $400 \mathrm{~km}$ (B. Lyon et al. 2009). DoM provides farmers weekly bulletins, and seasonal monthly and quarterly forecasts.

98. The Japan International Cooperation Agency (JICA) is supporting the expansion of the country's meteorological capabilities, as well as other DRM initiatives. Its activities include (i) a project for improving meteorological observation, weather forecasting, and dissemination, which aims at improving DoM's capabilities in meteorological observation and forecasts/warnings for weather hazards through deployment of 38 automatic weather observation systems to improve weather observation capacity (JICA 2014b); (ii) a disaster management capacity enhancement project; and (iii) establishment of a disaster impact assessment system which assesses disaster control measures, designs, and construction methods in infrastructure development projects (JICA 2014a). 


\subsubsection{Microinsurance}

99. Microinsurance remains low, with total premium accounting for only $3.4 \%$ of total insurance premium in 2015 despite the country's high financial inclusion rate of around $\mathbf{9 8 \%}$ by $2009-2010$ (Tilakaratna 2012). Around $98 \%$ of the total microinsurance policies are life and personal accident insurance. The high financial inclusion rate reflects the convergence of the commercial banking and microfinance institutions in the country, with commercial banks targeting the lower-income groups and the microfinance sector targeting the middle- and upper-income levels, coupled with impressive human development indicators such as a literacy rate of $92.5 \%$, average longevity of 77.9 years, a low population growth rate of $0.73 \%$ (Microinsurance Network 2016) and a low poverty head count of $6.7 \%$. As such, it is surprising that microinsurance penetration has not taken off in a big way (Table 4).

Table 4: Key Microinsurance Indicators in Sri Lanka, 2015

\begin{tabular}{|lc|}
\hline Indicator & Quantity \\
\hline Microinsurance penetration & $6.9 \%$ \\
\hline Number of policies & 1.46 million \\
\hline Gross written premium & $\$ 16$ million \\
\hline $\begin{array}{l}\text { Percentage of microinsurance premium to the } \\
\text { total general industry premium }\end{array}$ & $3.4 \%$ \\
\hline Annual average premium & $\$ 2-\$ 170$ \\
\hline Average claims ratio & $34 \%$ \\
\hline Average administrative cost & Not known \\
\hline Source: Microinsurance Network (2016). & \\
\hline
\end{tabular}

100. Microinsurance is generally not viewed in Sri Lanka as a commercially viable proposition. Only a few insurance companies have used their distribution platforms to reach microsegments with simple but traditional insurance products (see Table 5). The main challenges are as follows according to the Microinsurance Network (2016):

(i) the high administrative cost in reaching and serving this market segment, where registered insurers are more willing to participate in large ticket business rather than microinsurance;

(ii) the limited capacity of microinsurance clients to pay premiums and maintain their policies;

(iii) the lack of specific and proportionate regulations and institutions to promote the microinsurance sector;

(iv) the lack of skilled personnel to educate, canvass and service this segment;

(v) the significant role played by the informal microinsurance sector in reaching out to the low-income segment;

(vi) the absence of special regulatory provisions for microinsurance; and

(vii) low customer awareness. 


\section{Table 5: Microinsurance Products in Sri Lanka, 2015}

\begin{tabular}{|lr|}
\hline Class & Share (\%) \\
\hline Life & 40.4 \\
\hline Personal Accident & 57.5 \\
\hline Property & 0.8 \\
\hline Agriculture & 0.8 \\
\hline Livestock & 0.4 \\
\hline Health & 0.2 \\
Total & $\mathbf{1 0 0 . 0 0}$ \\
\hline
\end{tabular}

Source: Microinsurance Network (2016).

\subsubsection{Diagnostic and Recommended Actions}

101. Several actions are required to enhance credibility in the insurance sector and the capital markets. These actions include (i) further advancing the observance of international regulatory and supervisory standards as set by the International Association of Insurance Supervisors (IAIS) and the International Organization of Securities Commissions (IOSCO); (ii) increasing the resilience against adverse events of NITF, AAIB, and SLIC, which play an important role in maintaining solvency of the insurance sector and insuring public assets; and (iii) raising insurance awareness.

102. The credibility of the insurance sector could be enhanced by carrying out an assessment against the IAIS insurance core principles and standards. A higher level of observance of these principles would strengthen the resilience of the insurance sector; help assess any capacity-building needs of IRCSL staff and the sufficiency of market conduct aspects; and attract foreign participants to the market with new products, technology, and capital.

103. The IRCSL recently implemented changes in regulation and supervision ${ }^{32}$ that, while positive, also created important challenges that need to be managed:

(i) The new capital framework needs to be calibrated to the level of resilience that IRCSL considers prudent, and enhanced to include risk capital for catastrophic exposure.

(ii) Strong risk management, including regular stress testing at the company level and other forward-looking risk management tools, should be required to further improve the resilience of the insurance sector, including its disaster resilience.

(iii) Macro-prudential supervision should be enhanced and assessments of possible systemic risk and marketwide stress scenarios, including major catastrophic events, should be introduced as part of the supervisory regime.

(iv) IRCSL should consider moving into risk-based supervision to take full advantage of the risk-based capital framework and to optimize the use of the limited resources,

${ }^{32}$ IRCSL has modernized its supervision by recently introducing a risk-based capital framework; requiring insurers to be listed as companies or belonging to a listed group; and forbidding composite insurers (life and non-life insurance can no longer be offered by a single entity). 
allocating resources according to risk rather than allocating the same amount of resources to all activities.

(v) Staff training and capacity development in the new supervisory regime is critical and needs to be addressed.

104. A few insurance companies are not compliant with the mandatory separation of life and non-life operations or the listing requirements. Any breach of compliance with regulatory requirements, especially by a government-owned company such as SLIC, undermines credibility in the sector and the regulatory enforcement powers of IRCSL. Listing of insurers will also improve governance. It is urgently recommended that all insurers, including SLIC, comply with regulation by segregating all life and non-life business and listing all insurance companies.

105. Further growth in the size and sophistication of the capital market will require enhancements in its infrastructure and regulation. Notwithstanding the significant advances made in recent years, substantial and challenging structural and policy reforms are required. A $2016 \mathrm{ADB}$ assessment of the capital markets points to the need for major reforms to establish a well-functioning financial system with more broad-based, efficient and stable capital markets and to fully leverage its potential to achieve long-term economic objectives (ADB 2016). Enhanced credibility of the capital markets would also increase the significance of being a listed entity, as is now required for all insurance companies, and enhance opportunities to introduce disaster-related insurance-linked securities (ILS). Drawing and building on the 2016 ADB assessment, critical issues that need to be addressed to improve credibility in the capital markets include the following:

(i) The SEC Act should be amended to improve its observance of IOSCO principles and provide it with the necessary capacity to supervise a more sophisticated market.

(ii) SEC regulatory powers, which at present only covers criminal activity, should be enhanced with regard to security law violations.

(iii) The supervision of auditors should be assigned to the SEC or to another equivalent body to enhance the credibility of listed companies.

(iv) To encourage the take up of disaster insurance, listed companies should indicate the extent to which their properties, stock, liability, and other assets are insured, and which disaster contingency plans are in place.

(v) The demutualization of the Colombo Stock Exchange, which has been in the planning stage for several years, should be carried out to benefit competition and promote the development of the exchange.

(vi) A single, transparent, secondary market trading system with a market-making mechanism for government securities should be urgently established.

(vii) A central counterparty system and a clearing house for exchange-listed and government securities should be established and regulated.

(viii) An evenly-distributed maturity structure for government securities, spanning both medium- and long-term segments, should be established to avoid debt bunching and refinancing risks, which are particularly associated with disasters.

(ix) The capital market knowledge and skills of market participants and investors should be significantly strengthened across all capital market sectors, including equity, bonds, unit trusts, derivatives, and commodities.

(x) The financial market qualification system should be expanded to a multilayered licensing framework to accommodate all asset classes and facilitate capital market development. 
106. Proper risk management of NITF is critical for the solvency of the insurance sector and the protection of the public sector and the uninsured population. Strengthening the capacity and transparency of NITF would enhance resilience of the insurance sector. Thus,

(i) Mandatory retrocession agreements for NITF should be considered.

(ii) The procurement process of retrocessions should be enhanced.

(iii) Capitalizing NITF and developing its capacity would allow it to diversify its portfolio from its current concentration on Sri Lanka to take on global, or at least regional, risks. This would substantially elevate NITF's negotiation capacity when placing its retrocession program internationally.

(iv) Segregating the direct business of NITF, together with capacity building and the development of a national disaster risk model covering all major perils, would enable NITF to negotiate sustainable reinsurance support from the international market and discipline the market with technical rates for their individual catastrophic exposures.

(v) NITF could be a logical signatory of catastrophe bonds (section 3.3.4), thus providing additional disaster resilience to its operations.

107. SLIC's resilience is central for the credibility of the sector and the protection of public assets. While SLIC is well capitalized, its investment assets are exposed to high volatility. With about $96 \%$ of the equity investment of its shareholders in equities, its market exposure is high. In addition, notwithstanding its strong liquidity position, the payout of a large claim could lead to liquidity crunches as the capital might not be easily commuted into cash. It is recommended that SLIC should move toward a more balanced mix in its equity investments, and that its liquidity risk, both in life and non-life in the event of a major disaster, should be assessed.

108. The creation of a level playing field in the insurance and reinsurance sectors will encourage private sector participation in disaster risk transfer products. The benefits enjoyed by AAIB and NITF when providing insurance hinder private sector competition, which could generate better prices and products relevant for disaster risk insurance.

(i) Establishing a level playing field in the insurance sector would encourage technical pricing and fair competition. Mandated by the law, SLIC and NITF enjoy a monopoly on the public-sector insurance. SLIC has a dominant market position, which creates an important entry barrier for other insurers to provide coverage for state assets. On the other hand, NITF competes with its reinsured clients for statecontrolled insurance business. NITF should be encouraged to segregate its direct insurance activity, restrict its role to that of a national reinsurance provider, and open the market in public asset insurance to competition so that government institutions and entities can have access to competitive terms and premiums.

(ii) IRCSL should supervise AAIB's insurance activities. If AAIB, a critical institution in the country's DRF framework, is regulated by IRCSL, it would provide an even playing field in the agricultural insurance market for other insurance companies who presently compete with AAIB while also complying with risk-based capital and regulatory requirements. In addition to AAIB and NITF, a few private insurers offer crop, livestock and plantation insurance to clients in Sri Lanka. These include indemnity-based products for crops and livestock and weather index insurance for rice and tea farmers in selected locations (section 3.3.3). Losses induced by disasters 
are insured under both products. However, such products face competition from the subsidized products offered by AAIB. The provision of crop insurance by AAIB is further linked to that of the subsidized fertilizer of the government and hence driven in an involuntary manner. This creates market imperfections which can reduce investment by the private sector in a highly capital- and information-intensive business such as agricultural insurance.

109. The activities of AAIB regarding agricultural insurance should be separated from its role as farmers' and fishers' pension provider. AAIB's business covers (i) agricultural insurance underwriter and (ii) farmers and fisher's pension provider. It currently runs a composite activity of insurance and pension provisions through its 25 district offices and over 300 employees. AAIB's agricultural insurance business should be run on sound insurance principles supported by capital commensurate with the risks underwritten..$^{33}$ Further, the pension operations of AAIB impede the capital assessment of the agricultural insurance operations and thus directly bear upon the AAIB's ability to evaluate its agricultural insurance obligations.

110. The country's network of automated weather stations, weather forecasting, and data modeling skill sets need to be further expanded. Notwithstanding important developments in the infrastructure and capabilities of the meteorology department, the weather station infrastructure, farm advisory services (e.g., regarding timing of planting), and data repository systems in the DoM's offices across the country need to be enhanced to provide a strong backbone to agricultural insurance product pricing and design. At present, weather data is not centrally available from the approximately 200 weather stations (manual and automatic) across Sri Lanka (section 3.2.3). Similarly, crop yield data necessary for area yield index insurance needs to be captured within a central database. The modeling and predictive analytics regarding the frequency and severity of losses would benefit from access to a repository of farm exposures, area yields, and crop loss data, thereby improving product design and tools for ratemaking.

111. The resilience and sustained growth of the microinsurance sector is critical for providing disaster protection to the low-income population. The following actions are recommended:

(i) Develop microinsurance regulation. Microinsurance regulations can stimulate the growth of this sector by providing a strong regulatory framework, enhance the transparency levels of microinsurance providers, provide effective grievance handling platforms for underprivileged communities, develop a solid database for conducting market research, encourage product innovation and competitive pricing, facilitate reinsurance support, and promote outreach to remote rural areas.

(ii) Incentivize the insurance sector to engage in microinsurance. One of the barriers to the entry of commercial insurers into the microinsurance sector is the high administration cost in reaching out to communities located in remote areas. The government needs to incentivize the insurance sector by providing them smart subsidies by way of tax exemptions, and lower minimal capital and proportionate solvency requirements for dedicated microinsurance providers.

${ }^{33}$ Insurance Core Principle 4.6.1 states that legislation should categorize insurance business into types and classes of insurance (at least into life and non-life business). 
(iii) Create market awareness. Almost all the ingredients for developing a vibrant microinsurance market already exist in the country. However, one major barrier that remains concerns the lack of customer knowledge about the benefits of insurance. Recent research indicates an average claims ratio of only $34 \%$, suggesting limited understanding about insurance and claiming mechanisms (Microinsurance Network 2016). In this context, efforts to create awareness of the benefits provided by NNDIS coverage would help individual households become familiar with the concept of insurance and develop their trust in such products, thereby strengthening future demand for disaster insurance.

(iv) Increase outreach by using modern technology. Enhanced use of technology is recommended to support wide outreach at a reasonable cost.

\subsection{Product Availability and Affordability}

\subsubsection{Insurance Products}

112. A wide range of traditional insurance products are available to the public. The insurance sector has made a wide range of traditional insurance products available to corporates and individuals (Box 4). The natural perils cover is obtained as an add-on to the basic fire and motor cover. Almost all fire policies are extended to cover natural perils. Most motor policies are extended too.

\subsubsection{The National Natural Disaster Insurance Scheme}

113. The uninsured enjoy disaster protection through the NNDIS. This free insurance protection, provided by the government to all the citizens regardless of their income levels, commenced in April 2016 and covers disasters triggered by natural hazards such as tropical cyclones, storms, floods, landslides, and earthquakes but excluding droughts and man-made disasters. NNDIS covers damage up to SLRs2.5 million per event to properties and contents of uninsured homes and small business establishments. ${ }^{34}$ Property damage for large businesses and insured households are excluded. Accidental death for all victims of disasters triggered by natural hazards is covered up to SLRs 100,000 per life. The accidental death of fishers is covered up to SLRs1 million.

114. The total limit of liability in aggregate for the year ending 31 March 2017 was SLRs10 billion, comprising an annual limit of SLRs8.5 billion for structural damage to property and contents in respect of households and small business establishments, and an annual limit for emergency relief measures of SLRs1.5 billion. The government is the insured under the scheme and NITF is the insurer. The government paid SLRs300 million as premium for the NNDIS while NITF secured excess of loss reinsurance protection costing SLRs420 million for the year ending 31 March 2017.

115. The estimated loss of lives and damages to property from the May 2016 floods was SLRs3.5 billion. NITF paid the first SLRs500 million as per the reinsurance program.

\footnotetext{
${ }^{34}$ Any business with annual turnover not exceeding SLRs10 million.
} 


\section{Box 2: Traditional Insurance Products Available in Sri Lanka}

\section{Property}

- Advance loss of profit insurance

- Boiler explosion

- Burglary, fire, and theft for dwellings

- Business interruption

- Business interruption insurances connected with engineering insurance

- Combined package insurances such as hoteliers, shops, homes, and offices

- Contractor's all risks

- Contractor's plant and machinery

- Deterioration of goods in cold storage

- Electronic all risks

- Erection all risks

- Fire (dwellings, commercial, and tea factories)

- Machinery all risks

- Machinery breakdown

- Plate glass and neon signs

\section{Marine}

- Fishing boats

- Freight forwarder's insurance

- Goods in transit

- Import and export insurance

- Import and export open covers

- Marine hull and machinery

- Pleasure crafts

- Stock throughput insurance

\section{Motor}

- Comprehensive covers

- Third-party fire and theft and third-party liability only for private cars, commercial vehicles, motorcycles, three wheelers, and special types vehicles

- Trade plate insurance for garages and motor vehicle dealers

\section{Liability}

- Director's and officer's liability

- Product recall

- Products liability

- Professional liability

- Public liability

- Workmen's compensation or employer's liability

\section{Miscellaneous}

- Aircraft insurance

- All risks insurance

- Banker's indemnity or banker's blanket bond

- Cash in transit

- Fidelity guarantee

- Personal accident

- Surety bonds (bid, performance, advance payment, and retention)

- Surgical and hospital expenses

- Title insurance

- Travel insurance 
116. Unfortunately, Sri Lanka faced a further major floods and landslides in May 2017 at a time when NITF was not reinsured. At the time of the floods, the insurance policy with the government was effective without the backup reinsurance cover. NITF had renewed the insurance cover, at the request of the government, with an annual limit of liability of SLRs15 billion. The reinsurance arrangements had also been due for renewal on 1 April 2017 but this date was missed due to government tendering procedures. NITF had called for reinsurance quotes. Quotes in the region of SLRs0.8 billion toSLRs1.2 billion had been received but the government had only made available SLRs500 million as the premium for the policy. NITF therefore finally increased its own retention under the reinsurance program from SLRs500 million to SLRs1 billion to reduce the reinsurance cost. In the meantime, all the claims for the 2017 flood were met directly by NITF as the reinsurance was not in place at the time of the floods. The death toll from the May 2017 floods totaled 224, with 78 missing persons. Almost 700,000 people and around 179,000 families were affected. The number of houses and small establishments were not accounted as of the date reported by the press.

\subsubsection{Agriculture Insurance Products}

117. AAIB operates the flagship national crop insurance scheme with a premium rate of $1.5 \%$ of the sum insured. Under the Fertilizer Subsidy and Coupon System, a portion of the purchase price of subsidized fertilizer (SLRs150 per 50 kilogram bag) goes to cover the premium for crop insurance, providing a sum insured of SLRs10,000 per acre (SLRs22,222 per hectare). ${ }^{35}$ Due to the implied compulsory nature of this program, approximately 800,000 farmers (or 90\% of crop farmers) were insured under the scheme during 2014-2015 maha and 2015 yala seasons, covering $72 \%$ and $90 \%$ of the cultivated area, respectively. However, the crop insurance scheme suffers from two significant drawbacks: (i) low coverage, with only a fraction of the cost of cultivation insured, further punctuated by a decreasing scale from major irrigated crops to rain-fed crops; and (ii) lack of awareness of the scheme's benefits among beneficiaries. Under the subsidized crop insurance, AAIB provides traditional indemnity-based multi-peril crop insurance products for five crops-paddy, maize, potatoes, onions, soya bean, and chili. Perils insured are drought, flood, pests, diseases, and wild animal attacks. For each crop, a specific level of excess is applied-that is, losses above the excess are payable to the farmers. District level field inspectors assess claims through visual estimates as well as sample surveys. Underwriting losses for the subsidized crop insurance, if any, are paid from the crop insurance levy for which AAIB can approach NITF (section 3.1.2).

118. AAIB also offers indemnity-based crop insurance as well as other insurance products. AAIB's indemnity-based crop insurance policy charges a uniform rate across various crops and geographies in Sri Lanka, regardless of variations in disaster risk.

119. AAIB also offers (i) agricultural equipment insurance scheme (including coverage for tractors), (ii) warehouse insurance scheme, (iii) accident and health insurance schemes for farmers, and (iv) livestock insurance scheme for goats and cattle.

35 Before 2015, paddy farmers were given a significant amount of fertilizer at close to $90 \%$ of the fertilizer cost under the Fertilizer Subsidy and Coupon System. The government then made it mandatory for all farmers to buy crop insurance by increasing the price of a 50-kilogram bag of subsidized fertilizer to SLRs500 from the earlier price of SLRs350, the difference carved as compulsory premium for crop insurance scheme. All farmers were automatically enrolled in the insurance scheme at agrarian centers countrywide when they purchase subsidized fertilizers. However, in 2015, the prevailing government removed the fertilizer subsidy by introducing a coupon scheme. The coupon is worth SLRs25,000 per year. 
120. A few private insurers also offer crop, livestock, and plantation insurance. These include indemnity-based products for crops and livestock (Ceylinco General Insurance) and weather index insurance for rice and tea farmers (Sanasa Insurance Company) in select locations. Ceylinco General Insurance, Sanasa Insurance Company, and Cooperative Insurance Company also offer livestock insurance products. However, crop insurance products face competition from the subsidized products offered by AAIB. A summary of key agricultural insurance products is provided in Table 6.

\section{Table 6: Key Agriculturral Insurance Products Offered in Sri Lanka}

\begin{tabular}{|c|c|c|c|c|c|c|}
\hline Company & Measurement & Coverage & Pricing & $\begin{array}{l}\text { Sum insured } \\
\text { (SLRs) }\end{array}$ & $\begin{array}{l}\text { Credit- } \\
\text { linked? }\end{array}$ & $\begin{array}{l}\text { Irrigation- } \\
\text { related } \\
\text { exclusions }\end{array}$ \\
\hline AAIB & Indemnity & $\begin{array}{l}\text { All, } \\
\text { including } \\
\text { commercial } \\
\text { crops }\end{array}$ & $\begin{array}{l}\text { Flat rate, } \\
\text { SLR150 per } \\
\text { acre }\end{array}$ & $\begin{array}{l}\text { One-third of } \\
\text { cultivation } \\
\text { cost (e.g., } \\
\text { SLRs10,000 } \\
\text { per acre for } \\
\text { rice) }\end{array}$ & $\begin{array}{l}\text { Yes, } \\
\text { through } \\
\text { Bank of } \\
\text { Ceylon } \\
\text { and } \\
\text { Peoples' } \\
\text { Bank }\end{array}$ & $\begin{array}{l}\text { Rain-fed } \\
\text { crops } \\
\text { excluded }\end{array}$ \\
\hline Ceylinco & Indemnity & Select crops & $\begin{array}{l}\text { Differential } \\
\text { rate (e.g., } 8 \% \\
\text { of the sum } \\
\text { insured for } \\
\text { rice) }\end{array}$ & $\begin{array}{l}\text { Cultivation } \\
\text { cost + } \\
\text { margin (e.g., } \\
\text { SLRs50,000 } \\
\text { per acre for } \\
\text { rice) }\end{array}$ & $\begin{array}{l}\text { Can be } \\
\text { credit- } \\
\text { linked }\end{array}$ & $\begin{array}{l}\text { Rain-fed } \\
\text { crops } \\
\text { excluded }\end{array}$ \\
\hline $\begin{array}{l}\text { Cooperative } \\
\text { Insurance } \\
\text { Company }\end{array}$ & Indemnity & $\begin{array}{l}\text { Livestock, } \\
\text { cows and } \\
\text { goats }\end{array}$ & $\begin{array}{l}\text { Approximately } \\
4 \% \text { of the } \\
\text { animal's value }\end{array}$ & $\begin{array}{l}\text { Varies by } \\
\text { animal (e.g., } \\
\text { SLRs } 250,000 \\
\text { for cows) }\end{array}$ & No & NA \\
\hline $\begin{array}{l}\text { Sanasa } \\
\text { Insurance } \\
\text { Company }\end{array}$ & $\begin{array}{l}\text { Index, trigger } \\
\text { usually } 20 \% \\
\text { below average } \\
\text { parameter }\end{array}$ & $\begin{array}{l}\text { Mostly tea } \\
\text { and rice, } \\
\text { also covers } \\
\text { banana } \\
\text { crops }\end{array}$ & $\begin{array}{l}\text { Differential } \\
\text { rate, minimum } \\
4 \% \text { of the sum } \\
\text { insured }\end{array}$ & $\begin{array}{l}\text { Cultivation } \\
\text { cost (e.g., } \\
\text { SLRs } 30,000 \\
\text { per acre for } \\
\text { rice) }\end{array}$ & $\begin{array}{l}\text { Not } \\
\text { always, } \\
\text { although } \\
\text { Sanasa } \\
\text { Credit } \\
\text { Societies } \\
\text { can insist }\end{array}$ & $\begin{array}{l}\text { No specific } \\
\text { exclusions, } \\
\text { minor } \\
\text { irrigation } \\
\text { crops } \\
\text { are also } \\
\text { covered }\end{array}$ \\
\hline
\end{tabular}

AAIB = Agricultural and Agrarian Insurance Board, NA = not applicable, NITF $=$ National Insurance Trust Fund, SLRs = Sri Lanka rupee.

Source: Asian Development Bank.

121. Sanasa Insurance Company distributes its weather-based crop insurance and livestock insurance products through its approximately 8,000 Sanasa societies spread across Sri Lanka. The Sanasa Credit Societies act as lenders and function primarily on cooperative principles. Crop insurance product development started in 2009 under an International Labour Organization (ILO) grant for weather index insurance that the International Finance Corporation (IFC) further assisted with technical support. In 2012, Sanasa Insurance Company also commenced livestock insurance products. In FY 2016, agricultural insurance premiums of SLRs76 million were generated. Being a small insurance company, Sanasa reinsures $25 \%$ of its risks under a proportional reinsurance treaty. Crop insurance products are offered for rice, tea, and banana on a parametric/index basis 
(e.g., rainfall index for rice and tea, and wind-speed index for banana), and cover both minor irrigation and rain-fed crops. Claim triggers typically start at $+/-20 \%$ of the average parameter. The products are offered on a group insurance platform through the Sanasa cooperatives. Product development is often informed by representatives from the Sanasa cooperatives, thus it is likely to be voluntarily purchased by farmers. Loss ratios are high for rice and banana crops (approximately 100\%) and low for tea (approximately 30\%). Sanasa Insurance Company relies on weather station infrastructure for its weather index insurance and has ordered 35 new weather stations under a donor-assisted project to strengthen this network and thus its product.

122. Ceylinco General Insurance Company offers a multiperil-indemnity insurance product. The multiperil indemnity-based policy covers farmers for up to $60 \%$ of the sum insured if the loss occurs between 7 and 30 days after sowing; up to $80 \%$ if it occurs 31 or more days after sowing and before the flowering stage; and up to $100 \%$ of if the loss occurs between flowering and harvesting. Livestock insurance is offered with $10 \%$ excess and sum insured on the animal's value. Fishers can avail of a personal accident policy that covers being lost at sea.

\subsubsection{Capital Market Products}

123. The capital market in Sri Lanka has been growing fast, increasing from $\mathbf{3 0} \%$ of GDP in 2012 to $61 \%$ of GDP at the end of 2017. With its modern stock market dating back 32 years, the regulatory, institutional, trading, clearing, and settlement infrastructures are well-established. The Colombo Stock Exchange has 8 branches, 33 stockbrokers, 14 stock dealers, 14 unit trust management companies, 74 unit trust funds, 28 investment managers, 30 margin providers, 8 underwriters, and 2 credit rating agencies (SEC 2016).

124. However, there is not a wide range of products available on the market. The capital market primarily consists of government securities, stocks, and a minimal amount of corporate bond markets, with a combined value of $\$ 54$ billion as of 2016. The government securities market is the dominant sector, with a value of $\$ 32$ billion in 2016, whereas the stock market capitalization totaled $\$ 19$ billion. Less than $\$ 3$ million corresponded to corporate debt as of 2016 (Table 7).

\section{Table 7: Size and Composition of Capital Markets of Sri Lanka in 2016}

\begin{tabular}{|c|c|c|c|c|}
\hline \multirow[b]{2}{*}{ Capital Markets } & \multicolumn{4}{|c|}{ Value of Capital Market Asset Classes } \\
\hline & SLR Billion & \$ Billion & $\begin{array}{c}\% \text { of Total } \\
\text { Capital Market }\end{array}$ & $\%$ of GDP \\
\hline Government Securities ${ }^{\mathrm{a}}$ & $4,924.70$ & 32.10 & 60.05 & 36.69 \\
\hline Treasury Bills & 807.10 & 5.27 & 9.84 & 6.01 \\
\hline Treasury Bonds & $4,117.60$ & 26.87 & 50.21 & 30.68 \\
\hline Stock Market Capitalization & $2,899.29$ & 18.92 & 35.35 & 21.60 \\
\hline $\begin{array}{l}\text { Corporate Debt Market } \\
\text { Capitalization }\end{array}$ & 376.90 & 2.46 & 4.60 & 2.81 \\
\hline Total & $8,200.89$ & 53.52 & 100.00 & 61.10 \\
\hline
\end{tabular}

GDP = gross domestic product.

a Face value of outstanding government securities.

Source: Central Bank of Sri Lanka (2017). 
Insurance-Linked Securities

125. Currently not available in Sri Lanka, insurance-linked securities (ILS) are innovative financial products that are used to transfer insurance risk to capital market investors. ILS bonds, including catastrophe bonds and other forms of risk-linked securitization, represent assets whose value is largely driven by the occurrence of events that are not correlated with global financial market movements, offering significant portfolio diversification. With an ILS bond, the investor is exposed to a well-defined catastrophic event in addition to the credit risk of the issuer. For this additional exposure, investors are compensated with higher coupons and if no covered event occurs during the life of the bond, the bonds are redeemed at $100 \%$ of face value. However, if a covered event meeting the thresholds set forth in the risk transfer contract occurs, the investors stand to lose coupon payments and/or a percentage of the principal. The redemption price of the bonds is reduced accordingly. For more details, see the companion report Toolkit for Insurance, Reinsurance and Capital Market Solutions for Disaster Risk Financing (ADB, forthcoming).

126. Catastrophe (cat) bonds remain the dominant type of ILS globally. Other types of ILS include those based on mortality rates, longevity, and medical claim costs. As of 28 December 2017, the global ILS issuance for $2017 \mathrm{had}$ risen to $\$ 12.5$ billion up from $\$ 7$ billion in 2016 and the outstanding market had increased from $\$ 26.8$ billion in 2016 to $\$ 31$ billion in $2017^{36}$

127. Typical investors include life insurers' pension funds, mainly adding catastrophe risk into their investments to diversify their exposure to market risk. To a lesser extent, non-life insurers are also investing in ILS, assuming mortality and morbidity risks. Other institutional investors, including hedge funds searching for yield in a global low interest rate environment, are looking at ILS favorably too.

128. Insurers, reinsurers, and governments have been the traditional issuers of ILS, seeking to download their underwriting exposure into the global capital markets. The Government of Mexico is an active issuer of catastrophe bonds, ${ }^{37}$ both for earthquakes and hurricanes. It has secured cover through four cat bonds and received payouts under two of them. The costs of those instruments can be as high as $9 \%$ over LIBOR covering the frequent Atlantic hurricanes of category 4 or higher ( $\$ 210$ million for 2.5 years issued in 2017). The trigger for earthquake protection of the cat bond issued in 2017 was set at magnitude 7.9 or higher for a cost of $4.12 \%$ over LIBOR. This bond paid out $\$ 150$ million as a consequence of the 2017 8-magnitude Chiapas earthquake. ${ }^{38}$

\subsubsection{Diagnostic and Recommended Actions}

129. Insurance, reinsurance, and capital market product availability needs to be enhanced with specific reference to DRF. The current focus of the insurance sector is mainly on corporate insurance, which is served with a variety of traditional and packaged

${ }^{36}$ See The Artemis Catastrophe Bond and Insurance-Linked Securities Deal Directory at http://www.artemis.bm/ deal_directory/.

${ }^{37}$ K. Llanos-Small. 2017. Mexico vs Cat bonds: 1-1. Global Capital. 12 October. https://www.globalcapital.com/article/ b154ccrzv0yhcd/mexico-vs-cat-bonds-1-1.

38 The devastating 7.1 magnitude earthquake in central Mexico in 2017 did not trigger this cat bond because it was below the 7.9 magnitude trigger level. 
products. Retail- and/or personal-lines insurance demand is low and mainly purchased to meet legal requirements, such as compulsory third-party motor insurance and/or to meet leasing or financial institution requirements, e.g., pertaining to bank loans and leasing facilities. Private sector insurers have not ventured into microinsurance products due to significant marketing and distribution costs. Therefore, the necessary distribution channels and products to service individuals have not been sufficiently developed.

130. The NNDIS has provided important financing to cope with disaster losses. Within a few months following the establishment of the NNDIS, severe floods in May 2016 triggered payouts under the scheme. However, to maintain sustainability of coverage, a better design is required.

(i) Separation between the insured and the insurer and an improved system to assess loss and identify eligible beneficiaries must be established. Currently, the government, through the state-owned NITF, is both the insurer, the policyholder, and the loss adjustor, with loss adjustments carried out through provincial authorities. Under this structure, any international reinsurer will have concerns regarding the proper functioning of the insurance coverage. These concerns, especially following the May 2016 losses, will limit the interest of international reinsurers in supporting the NNDIS at a reasonable price.

(ii) Levels of compensation need to be adjusted to reflect the post-disaster financing needs of the uninsured. This would strengthen the performance of government in meeting its responsibility to provide adequate disaster risk protection for the uninsured who cannot afford insurance premiums. In determining appropriate levels of compensation, NNDIS cover could perhaps be means tested to avoid crowding out direct uptake of insurance from the private sector by households that can afford it and to allow higher compensation to poorer households through the NNDIS.

(iii) The NNDIS's positive experience for the public should be strongly communicated to the public. The government is recommended to enhance awareness of the benefits and positive past payout experience that the NNDIS has provided to the uninsured to help boost understanding and trust in insurance.

131. Environmental liability insurance, which is linked with climate change and thus with changing disaster risk, also needs to be developed (ADPC 2013). Past events affecting the environment and the subsequent financial impact in the form of fines and liabilities on the entities responsible for the ensuing damage have raised awareness of the need to purchase environmental liability insurance. However, this type of insurance is not well-developed in Sri Lanka and, as such, the costs are high and availability of coverage is limited. The introduction of mandatory insurance against environmental damage for industries that have the potential to harm the environment would not only make funds available to repair the environmental damage and compensate those affected, but would also require said industries to implement proper risk management measures as a precondition to obtaining such insurance. The certification of proper risk management systems would have to be undertaken by a credible and knowledgeable institution to be established in Sri Lanka. This could be done with the support of donors for a period of, say, 5 years until the needed capacity is available in the country. The mandatory character of such an insurance would lower costs through a wide base and no adverse selection effects. 
132. Sri Lanka does not have derivatives or commodities exchanges that could play an important role in DRF. It is important to assess economic and market fundamentals and ensure that the necessary regulatory, trading, clearing, and settlement infrastructures are in place for the introduction of derivatives and commodities products. As the $2016 \mathrm{ADB}$ assessment of capital markets in Sri Lanka stated, a realistic road map with proper sequencing of initiatives is needed before derivatives and commodities can be introduced (ADB 2016). Stock index futures, treasury bond forwards and futures, individual stock options, and tea futures have the potential to play an important role in the development of the derivatives and commodities markets. Eventually, ILS should be introduced.

133. The government could take advantage of ILS, including catastrophe bonds, as an addition to its existing DRF instruments. While the current level of sophistication of the capital markets and country rating do not allow for an efficient introduction of ILS for disaster risks, the government could still take advantage of these instruments. The appropriate instruments would be ILS issued by an AAA-rated entity that include as triggers disasters affecting Sri Lanka. In this case, the government could contribute to the ILS risk premium in exchange for access to the funds should the trigger event occurs. Depending on the risk appetite of global markets and the government's disaster protection needs, the triggers could possibly be defined to cover extreme weather events, or significant earthquake events, which are currently perceived as very low risk, and hence could attract a low risk premium in global markets. Bonds linked to tsunamis could also be of interest. ${ }^{39}$

\subsection{Social Protection}

134. There is important involvement of the government in providing social security benefits that could be crowding out the private sector initiatives. In low- and middleincome countries with low insurance penetration and significant poverty levels, governments take on the role of insurers of last resort. In the case of Sri Lanka, special dedicated entities are in place to support the low-income population. For instance, the Samurdhi Authority under the Department of Samurdhi Development of the Ministry of Social Empowerment (which focuses on poverty alleviation) is involved in microinsurance and provides personal lines insurance coverage to almost 1.42 million families. ${ }^{40}$ To complement this protection, the government has introduced the NNDIS to provide disaster cover to all uninsured lives and property.

135. Well-designed public social protection programs can have a potentially positive, rather than a crowding-out, impact on the growth of the microinsurance sector. Properly structured government-sponsored safety nets and strictly regulated community-run programs can act as catalysts for stimulating market growth.

39 Note that ILS should be considered as optional DRF instruments that, depending on the particular DRF strategy of the country, may or may not be useful.

40 The Samurdhi Authority under the Department of Divineguma Development provides vulnerable households a monthly cash transfer, as well as deducts SLRs100 per household toward the insurance cover to reduce their vulnerabilities in the event of childbirth, marriage, illness, and death. In cases of hospitalization, the insurance provides payouts to the families (Microinsurance Network 2016). 


\subsubsection{Government-Sponsored Programs}

136. The Ministry of Social Empowerment, Welfare and Kandyan Heritage, whose main objective is the eradication of poverty, has provided Samurdhi benefits to lowincome households since $1995{ }^{41}$ The Upcountry Development Authority, Southern Development Authority and Upcountry Peasants, Samurdhi, and Divineguma are under the purview of this Ministry through an Act of Parliament.

137. The Government of Sri Lanka provides free health service to all citizens through the National Health Services. In addition, most private sector health policies are on a group basis, purchased by an employer as an additional fringe benefit for employees and their spouses and children. The minimum rate of premium is about $10 \%$ of the annual limit of liability. Private health insurance provides patients with the funds to undergo any treatment or surgery at a hospital of their choice and the ability to consult the best available medical consultants and specialists. However, medical insurance premiums are not cheap and many cannot afford them.

138. Since January 2006, NITF has administered the Agrahara Medical Insurance Scheme for public servants. Introduced by the Ministry of Public Administration, the main objective of this scheme is to uplift the living standards of the public service and provincial public service and their families. Approximately 700,000 public servants and their dependents are catered for through this scheme. ${ }^{42}$

\subsubsection{Community-Based Organizations' Sponsored Programs}

139. Several community-based organizations and NGOs are involved in providing insurance to their members. For instance:

(i) Yasiru operates in six districts and has less than 10,000 members. It offers insurance protection for death due to accidental or natural causes, and for total permanent or partial permanent disability. The scheme has a maturity benefit on reaching the age of 75 years.

(ii) Sarvodaya Economic Development Services Ltd (SEEDS) is a microfinance institution that covers around 3,000 village societies with around 300,000 savers and 150,000 borrowers. SEEDS offers a credit life insurance policy.

(iii) The Women's Development Foundation ${ }^{43}$ in Hambantota district provides microinsurance to its members.

(iv) Funeral societies have operated in Sri Lanka for a long time. Each village has at least one, and in some cases more than one, funeral society or death donation scheme. In addition to providing financial support during bereavement, some societies have extended their benefits to include hiring of chairs, sheds or tents, and sound systems and other amenities for funerals (Microinsurance Network 2016).

${ }^{41}$ Department of Samurdhi Development. http://www.samurdhi.gov.lk/web/index.php?lang=en.

${ }^{42}$ National Insurance Trust Fund. Agrahara Insurance. http://www.nitf.lk/ENGLISH/Agrahara.html.

${ }^{43}$ Women's Development Federation. http://www.wdfsl.org. 


\subsubsection{Diagnostic and Recommended Actions}

140. Commercial insurers should be allowed to participate in government-sponsored insurance programs to bring in more transparency, speed and efficiency, thereby ensuring their long-term sustainability. The government does not have unlimited resources to cater to the growing needs of its citizens and should gradually pass on this responsibility to the insurance industry. Public-private partnerships should be promoted so that commercial insurance companies can fill in the gaps and shortcomings in the government-sponsored programs, namely the health scheme and the NNDIS. These partnerships can bring significant benefits to the government by improving the scope of coverage, pricing structures, and service levels of these schemes. A cost-benefit analysis of the current schemes should also be conducted, along with a study of their impact on the growth and development of the insurance sector.

141. Unlicensed competition is a significant issue that needs to be addressed. The Regulation of Insurance Industry Act No. 43 of 2000 does not include any provision on the regulation of mutual insurance companies. Some mutual insurance companies writing microinsurance business are also not regulated or supervised by IRCSL and are not required to have capital commensurate to the risk they are accepting from the insured, leaving it unclear whether they would be able to honor their commitments after a major disaster. The incorporation of mutual insurance companies, NGOs, and community-based organizations offering microinsurance products but acting outside the insurance law, into a proportionate regulatory regime under the purview of IRCSL is recommended. 


\section{The Rating Summary and Recommended Main Actions}

142. The ideal enabling environment scenario for the growth of disaster risk financing instruments in Sri Lanka coincides to a vast extent with the achievable scenario. Thus, the gap analysis of the current scenario has been carried out against the ideal scenario. The insights gained in applying the diagnostics tool in Sri Lanka for the purposes of this country assessment indicated no significant differences between the ideal scenario and the realistic or achievable scenario. The responses from the stakeholders with respect to the realistic scenario were more along the way of providing additional solutions on how to achieve the ideal scenario rather than describing limitations that would hinder the realization of the ideal scenario. The figure presenting the ratings results thus shows only the current situation and ideal scenario (Figure 7).

\section{Figure 7: The Rating Results for Sri Lanka}

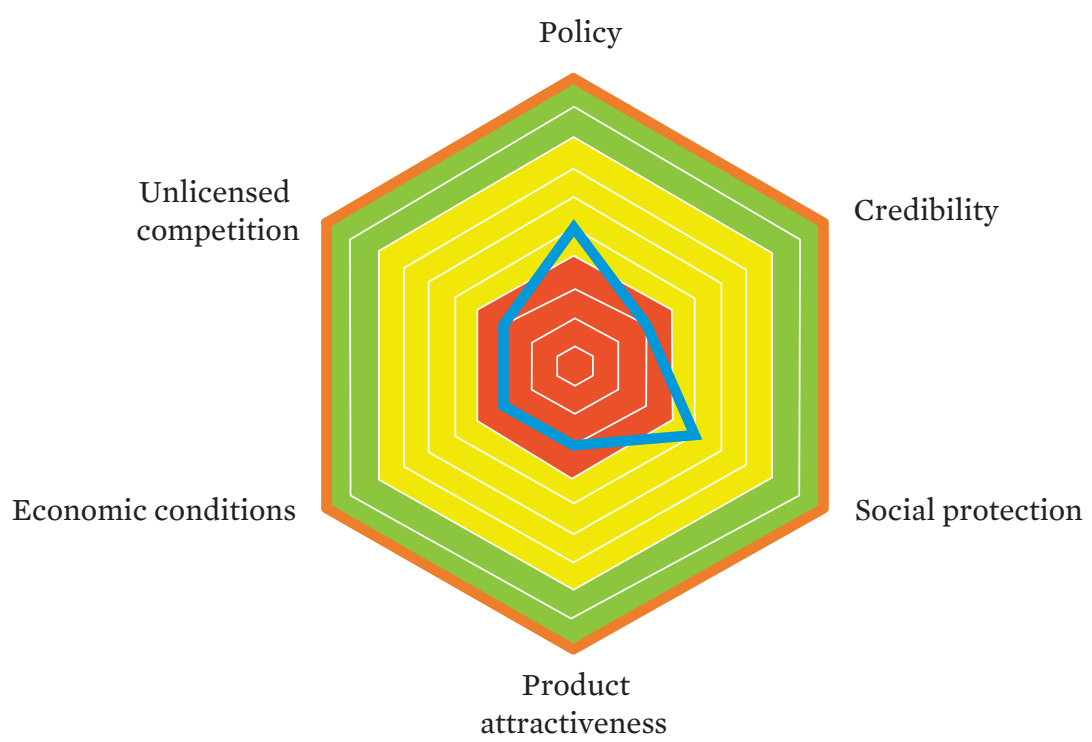

attractiveness 


\subsection{Gaps in, and Recommendations for, Government Policy}

143. The rating is in the yellow zone implying the need for action (sections 2.1, 2.2, and 3.1).

144. Main gaps identified:

(i) The Government of Sri Lanka has limited ex ante financing arrangements in place for post-disaster response, periodically placing significant demands on public resources.

(ii) The National Disaster Fund, created under the 2005 Disaster Management Act, is yet to be established.

(iii) There is no risk assessment for government-owned infrastructure and assets exposed to natural hazards.

(iv) The use of disaster risk transfer instruments by the government is ad hoc, rather than in accordance with a disaster risk financing strategy designed to maximize the costefficiency of the selected tools.

(v) The crop insurance levy strategy raises several questions regarding its effectiveness.

145. Main recommended actions to close the gaps:

(i) Develop a DRF strategy following the risk layering approach.

(ii) Establish the National Disaster Fund to provide a first layer of cover and allow funds to be rolled over between years.

(iii) Assess the state of disaster risk mapping and modeling and develop and implement a plan of action to develop comprehensive mapping and modeling with sufficient granularity to support the development of an effective DRF strategy.

(iv) Consider the use of contingent disaster loans.

(v) Formulate a government policy on the use of risk transfer instruments for DRF.

(vi) Support agricultural insurance with initiatives that holistically integrate the existing crop insurance levy's accumulated fund.

(vii) Develop insurance skill sets and capacity for key crops, e.g., rice and tea.

(viii) Explore insurance for smallholder tea growers.

\subsection{Gaps in, and Recommendations for, Credibility in the Insurance Sector and the Capital Markets}

146. The rating is in the red zone implying the urgent need for action (sections 3.2 and 3.3).

147. Main gaps identified:

(i) Recent changes in regulation and supervision that have been implemented by the IRCSL, while positive, also create important challenges that need to be managed. 
(ii) A few insurance companies are not compliant with the mandatory separation of life and non-life operations or the listing requirements.

(iii) Awareness and understanding of the concept of insurance is very low.

(iv) Regulation and supervision has not been assessed by international bodies for quite some time.

(v) There is no level playing field in the insurance and reinsurance sectors.

(vi) The risk management of NITF is insufficient to ensure the solvency of the insurance sector and to protect the public sector and uninsured population.

(vii) AAIB insurance activities are not supervised by the insurance regulator.

(viii) AAIB has conflicting roles as a provider of agriculture insurance and provider of pensions to farmers and fishers.

148. Main recommended actions to close the gaps:

(i) Assess the insurance sector against the IAIS insurance core principles and standards to enhance its credibility.

(ii) Enforce the segregation of life and non-life business for all insurers.

(iii) Develop customized insurance awareness programs for disaster insurance.

(iv) Enhance infrastructure and regulation of the capital markets.

(v) Create a level playing field in the insurance and reinsurance sectors.

(vi) Enforce advance risk management of NITF.

(vii) Supervise AAIB insurance activities.

(viii) Separate AAIB's activities in agricultural insurance from its activities as provider of pensions to farmers and fishers.

\subsection{Gaps in, and Recommendations for, Products}

149. The rating is in the red zone implying the urgent need for action (sections 3.2 and 3.3).

150. Main gaps identified:

(i) Retail insurance products are limited to motor insurance and personal accidents.

(ii) The NNDIS has provided important financing to provide compensation for disaster losses but its sustainability is fragile.

(iii) Sri Lanka does not have derivatives or commodities exchanges.

(iv) Insurance-linked securities (ILS) are not available.

(v) Environmental liability insurance is near non-existent.

151. Main recommended actions to close the gaps:

(i) Expand retail insurance products.

(ii) Amend the design of NNDIS to ensure its sustainability.

(iii) Develop derivatives or commodities exchanges that can play an important role as DRF instruments.

(iv) Introduce ILS as a DRF instrument.

(v) Develop environmental liability insurance. 


\subsection{Gaps in, and Recommendations for, Social Protection}

152. The rating is in the yellow zone implying the need for action (section 3.4).

153. Main gaps identified:

(i) Most of the responsibility for social protection of the low-income population rests on the government.

154. Main recommended actions to close the gaps:

(i) Allow commercial insurers to participate in the government-sponsored insurance programs for greater transparency, speed, and efficiency, thereby ensuring program sustainability for the long-term.

\subsection{Gaps in, and Recommendations for, Economic and Other Preconditions}

155. The rating is in red zone implying the urgent need for action.

156. Main gaps identified:

(i) Per capita GDP is very low and, as such, insurance is a relatively low priority, competing with food, housing, and clothing needs for a large segment of the population.

(ii) Weather data is presently not centrally available from the approximately 200 weather stations (manual and automatic) across Sri Lanka. Similarly, crop yield data necessary for area yield index insurance is not captured in a central database.

(iii) Microinsurance remains low, with total premium accounting for only $3.4 \%$ of total insurance premium.

157. Main recommended actions to close the gaps:

(i) Increasing the GDP per capital will support insurance consumption.

(ii) Expand the network of automated weather stations, weather forecasting, and data modeling skill sets and consolidate information centrally.

(iii) Develop exposure and loss statistics of crop yields.

(iv) A comprehensive microinsurance strategy will support its penetration. 


\subsection{Gaps in, and Recommendations for, Unlicensed Competition}

158. The rating is in the red zone implying the urgent need for action (section 3.4.3).

159. Main gaps identified:

(i) Unlicensed competition is a significant issue that needs to be addressed.

160. Main recommended actions to close the gaps:

(i) Incorporate NGOs and CBOs offering microinsurance products but acting outside the insurance law into a proportionate regulatory regime under the purview of IRCSL of the mutual insurance companies.

(ii) Develop microinsurance regulation to allow for a regulated and vibrant microinsurance sector. 


\section{APPENDIX \\ Key Learnings from International Experience in Agricultural Insurance}

1. Insurance should not be treated as a standalone solution, but as a package closely linked to wider risk management and adaptation efforts. These include social safety nets, early-warning and awareness-raising programs, disaster-proofing infrastructure, and investment in more sustainable livelihoods. Without a comprehensive response, there is a danger of creating a false sense of security, encouraging unwise risk-taking and a reluctance to adapt. ${ }^{1}$

2. There must be sustained, predictable, and long-term financial support to pay the premiums for vulnerable countries (macro-level insurance) and individuals (micro-level insurance) noting that, in most rich countries, insurance (e.g., for agriculture or flooding) is heavily subsidized by the government. ${ }^{2}$

3. Insurance is not efficient for many types of loss and damage, such as frequent events (more than 1 in 5 years), slow onset phenomena, and social or cultural losses. ${ }^{3}$

4. Agriculture insurance can only be fairly priced if reliable and granular data is available. Pricing with substandard data requires from actuaries to put a credibility margin. Thus, adding to the costs of covering the claims a penalty for the uncertainty in the data.

5. Agriculture-related data is required for many government activities, like for food safety and security, land planning, etc. In addition, the costs to collect data can be very large, especially when looking at weather data. It has become a main activity for government to collect agriculture and weather-related data to fulfill their obligations. The data collected by government can be a good starting point to make data for insurance available. However, insurance pricing requires more granular data and also other aspects like average yield per land, etc. Dialogue and cost sharing between the public and the private sector to collect data that is useful for both parties can be very beneficial for the country.

6. The need for reinsurance in agriculture that is exposed to catastrophic risk is a reality. Only global reinsurers will have the capacity and ability to diversify the potentially large risks. Reinsurers will collect their data and use models to price their exposure. However, the data needs to be complemented by local data. For instance, the availability of a dense set of weather stations is a requirement for some reinsurance programs. The need to develop this type of infrastructure is indispensable for the agriculture insurance supported by reinsurance to develop.

1 S. Surminski et al. 2016. WIM Submission: Best Practices, Challenges and Lessons Learned from Existing Financial Instruments.

2 World Bank. 2010. Government Support to Agricultural Insurance.

3 Munich Climate Insurance Initiative. 2012. Insurance Solutions in the Context of Climate Related Loss and Damage. 
7. By providing a layer of reinsurance, governments can support agriculture insurance programs over initial periods, when data sets are imperfect and while investments are being made in market data infrastructure. ${ }^{4}$ These governments can then offload the risk to reinsurance markets over time, as data quality improves and the coverage gap reduces.

4 World Bank. 2015. Agricultural Data and Insurance. page 5, para. 5. 


\section{References}

ADB. 2013. Investing in Resilience: Ensuring a Disaster-Resistant Future. Manila.

—. 2014. Operational Plan for Integrated Disaster Risk Management, 2014-2020. Manila.

. 2015. Technical Assistance for Strengthening the Enabling Environment for Disaster Risk Financing (Phase 1). Manila.

—_. 2016. Sri Lanka Capital Market Assessment. Consultant's report. Manila

. 2017a. Asian Development Outlook 2017. Transcending the Middle-Income Challenge. Manila.

2017b. Asian Development Outlook 2017 Update. Sustaining Development Through Public-Private Partnership. Manila.

- 2017c. Review of the 2011 Financial Sector Operational Plan. Manila.

—. 2018a. Asian Development Outlook 2018 Update. Maintaining Stability Amid Heightened Uncertainty. Manila.

—. 2018b. Economic Indicators for Sri Lanka. https://www.adb.org/countries/sri-lanka/ economy.

- Forthcoming. Report on Toolkit for Insurance, Reinsurance and Capital Market Solutions for Disaster Risk Financing. Manila.

ADB, JICA and the World Bank. 2005. Preliminary Damage and Needs Assessment: Sri Lanka 2005 Post-Tsunami Recovery Program. Colombo.

ADB and the World Bank. 2017. Assessing Financial Protection against Disasters: A Guidance Note on Conducting a Disaster Risk Finance Diagnostic. Manila and Washington, DC.

Agricultural and Agrarian Insurance Board. 2014 Annual Report. Colombo.

Asian Disaster Preparedness Center (ADPC). 2011. Mainstreaming Disaster Risk Reduction into Approval Permits of Development Activities in the Coastal Areas of Sri Lanka. Bangkok.

. 2013. Chemical Accident Prevention and Preparedness Programme Project in Sri Lanka. http://www.capp.eecentre.org/upload/images/proj_srilanka_Casestudy.pdf

Central Bank of Sri Lanka (CBSL). 2016a. 2016 Annual Report. Colombo.

—. 2016b. Sri Lanka Socio-Economic Data 2016. Colombo. p. 17.

Cereal Systems Initiative for South Asia. 2015. Mind the Gender Gap in Farmers' Preferences for Weather Index Insurance. http://csisa.org/wp-content/uploads/sites/2/2014/09/ CSISAResearch-Note-7.pdf.

Consumer Affairs Authority. 2003. The Consumer Affairs Authority Act No 09 of 2003. http://www.caa.gov.lk/web/index.php?option=com_content\&view=article\&id=111\& Itemid=560\&lang=en. 
Disaster Management Centre and United Nations Development Programme. 2009. Sri Lanka National Report on Disaster Risk, Poverty and Human Development Relationship. Colombo. http://www.preventionweb. net/english/hyogo/gar/background-papers/ documents/Chap3/Asia-overview/Sri- Lanka-DRAFT-march-09.pdf.

Europa. 2015. Existing Agricultural Insurance Systems in the World. Brussels. http://ec.europa. eu/agriculture/analysis/external/insurance/existing_en.pdf.

Food and Agriculture Organization of the United Nations (FAO). 2015. The Impact of Disasters on Agriculture and Food Security. Rome.

Government of Sri Lanka. 1975. Tea Small Holdings Development Act No. 35 of 1975.

_. 1987. Securities and Exchange Commission of Sri Lanka Act No. 36 of 1987.

—. 1999. Agricultural and Agrarian Insurance Board. Act No. 20 of 1999. Colombo.

- 2000. Regulation of Insurance Industry Act No. 43 of 2000.

- 2005. Sri Lanka Disaster Management Act No. 13 of 2005.

—. Ministry of Disaster Management, Disaster Management Centre. 2010a. Annual Report 2010. Colombo.

_. Ministry of Disaster Management. 2010b. National Policy on Disaster Management. Colombo.

—. Ministry of Environment. 2010c. Sector Vulnerability Profile: Agriculture and Fisheries. Supplementary Document to The National Climate Change Adaptation Strategy for Sri Lanka 2011 to 2016. Battaramulla.

—. Ministry of Finance and Planning. 2012a. Agricultural and Agrarian Insurance Board Act. 1999.

—. Ministry of Finance and Planning. 2012b. Annual Report 2012. Colombo.

- Ministry of Finance and Planning. 2013. Circular No. BD/EE/118/01/BP/2013, Colombo.

- 2014a. Sri Lanka Comprehensive Disaster Management Programme 2014-2018. Colombo.

- Ministry of Economic Development, Ministry of Disaster Management, and World Food Program. 2014b. Drought: Food Security and Livelihoods Affected by Erratic Weather. 21 June. http://documents.wfp.org/stellent/groups/public/documents/ena/ wfp265010.pdf?_ga=2.118458241.942438991.1497960167-266628491.1497433220.

—. Ministry of Finance and Planning. 2014c. Circular No. DFD/Circular/2014 - 03, Colombo.

- Ministry of Finance and Planning. 2016. Mahinda Chintana: Vision for a New Sri Lanka-A Ten Year Horizon Development Framework 2006-2016. Discussion Paper. Colombo: Department of National Planning.

- Department of Government Information, 2017a. The Government expands the crop insurance paid to paddy to other five main crops as well. 22 June. https://www.dgi.gov. lk/news/latest-news/1056-the-govt-expands-the-crop-insurance-paid-to-paddy-toother-five-main-crops-as-well. 
- Ministry of Finance and Planning, 2017b. Fiscal Management Report.

—_. Ministry of National Policies and Economic Affairs, 2017c. Vision 2025: A Country Enriched. Colombo.

GTZ. 2007. Basic Education and Disaster Risk Management: Concept Paper. Eschborn.

International Monetary Fund (IMF). 2016. IMF Survey: Sri Lanka to Reboot Economic Policies. , 14 June. 14, 2016, https://www.imf.org/en/News/Articles/2015/09/28/04/53/ socar061416a.

- 2017. Executive Board Completes Third Review of the Extended Arrangement Under the EFF with Sri Lanka and Approves US\$ 251.4 Million Disbursement. Washington, DC.

—. 2018. Sri Lanka: Third Review Under the Extended Arrangement Under the Extended Fund Facility and Request for Modification of Performance Criterion. Washington, DC.

Insurance Board of Sri Lanka. 2012 Annual Report. Colombo.

—. 2015. Annual Report. Colombo.

—. 2017. Fostering Growth: Annual Report 2016. Colombo.

JICA. 2014a. JICA's Cooperation on Disaster Management. Toward Mainstreaming Disaster Risk Reduction: Building Disaster Resilient Societies. http://gwweb.jica.go.jp/km/ FSubject0301.nsf/ff4eb182720efaOf49256bc20018fd25/3958a0a725aba98549257a7900 $124 f 29 / \$ F I L E / E . p d f$.

- 2014b. The Project for Improving of Meteorological Observation, Weather Forecasting and Dissemination in Democratic Socialist Republic of Sri Lanka. http://www.jica.go.jp/ srilanka/english/office/topics/c8h0vm000096mu2r-att/150417_01.pdf.

Llanos-Small, K. 2017. Mexico vs Cat bonds: 1-1 Global Capital. 12 October. https://www. globalcapital.com/article/b154ccrzv0yhcd/mexico-vs-cat-bonds-1-1.

Lyon, B., L. Zubair, V. Ralapanawe, and Z. Yahiya, Z. 2009. Finescale Evaluation of Drought in a Tropical Setting: Case Study in Sri Lanka. Journal of Applied Meteorology and Climatology, Vol. 48, Issue 1, pp. 77-88.

Microinsurance Network. 2016. The Landscape of Microinsurance in Sri Lanka 2016. Luxembourg. Munich.

Munich Climate Insurance Initiative. 2012. Insurance Solutions in the Context of ClimateRelated Loss and Damage. http://www.climate-insurance.org/fileadmin/mcii/ documents/20121112_MCII_PolicyBrief_2012_screen.pdf.

Patankar M., and N. Schweizer N. 2016. Agro Insurance Hotspot, Sri Lanka. Swiss Re. Zurich. http://www.swissre.com/library/Agro_insurance_hotspot_Sri_Lanka.html.

Securities and Exchange Commission of Sri Lanka (SEC). 2016. Building Bridges, Annual Report 2016. Colombo.

Surminski S. et al. 2016. WIM Submission: Best Practices, Challenges and Lessons Learned from Existing Financial Instruments. http://unfccc.int/files/adaptation/groups_ committees/loss_and_damage_executive_committee/application/pdf/submission_ld_ network.pdf. 
Tilakaratna G.M. 2012. Dimensions and Dynamics of Clientship in the Microfinance Sector: Evidence from Sri Lanka. (Unpublished doctoral dissertation). University of Manchester. Manchester, UK. https://utas.libguides.com/c.php?g=498348\&p=3412821.

United Nations Development Programme (UNDP). 2011. Final Report on Outcome Evaluation of Disaster Risk Management Programme of UNDP Sri Lanka. Colombo.

Wickramasinghe K. 2016. "Crop Insurance: Is It Workable in Sri Lanka?” Talking Economics. Institute of Policy Studies of Sri Lanka. http://www.ips.lk/talkingeconomics/2016/11/22/ crop-insurance-is-it-workable-in-sri-lanka/.

World Bank. 2010. Government Support to Agricultural Insurance. https://openknowledge. worldbank.org/bitstream/handle/10986/2432/538810PUB0Gove101OfficialoUse0On ly1.pdf? sequence $=1 \&$ isAllowed $=\mathrm{y}$.

- 2016a. Fiscal Disaster Risk Assessment and Risk Financing Options: Sri Lanka. Washington, DC. https://www.openknowledge.worldbank.org/handle/10986/24689.

—_. 2016b. Fiscal Disaster Risk Assessment, Options for Consideration, Sri Lanka. Colombo.

- . 2016c. Sri Lanka Development Update. Washington, DC. http://documents.worldbank. org/curated/en/622841476967944601/Sri-Lanka-development-update.

. 2016d. Sri Lanka-Ending Poverty and Promoting Shared Prosperity: A Systematic Country Diagnostic. Washington, DC. http://documents.worldbank.org/curated/ en/363391467995349383/Sri-Lanka-Ending-poverty-and-promoting-sharedprosperity-a-systematic-country-diagnostic.

World Food Programme. 2016. Sri Lanka Initial Rapid Assessment on Drought 2016. http:// documents.wfp.org/stellent/groups/public/documents/ena/wfp289877.pdf? $\mathrm{ga}=2.27735932 .1532618077 .1498110122-1029025688.1498110122$.

—. 2017. Sri Lanka Country Brief. http://documents.wfp.org/stellent/groups/ public/documents/ep/wfp273248.pdf?_ga=2.23361402.1532618077.14981101221029025688.1498110122 .

Zane, M. 2010. The Effects of Tsunami Relief Policy on Poverty Levels in Indonesia and Sri Lanka. Senior Thesis. Economics Department. New Jersey: The College of New Jersey. http://business.tcnj.edu/files/2012/02/Zane-thesis-added-2012.pdf. 


\section{The Enabling Environment for Disaster Risk Financing in Sri Lanka}

Country Diagnostics Assessment

This country diagnostic assessment seeks to strengthen financial preparedness for disasters in Sri Lanka, focusing on insurance and other risk transfer instruments. It explores the current application of disaster risk financing solutions by the government, businesses, and individual households; related demand and supply constraints; and opportunities for improvement. The assessment forms one of a series of country diagnostics undertaken using a common methodology to determine the state of the enabling environment for disaster risk financing.

\section{About the Asian Development Bank}

ADB is committed to achieving a prosperous, inclusive, resilient, and sustainable Asia and the Pacific, while sustaining its efforts to eradicate extreme poverty. Established in 1966, it is owned by 67 members48 from the region. Its main instruments for helping its developing member countries are policy dialogue, loans, equity investments, guarantees, grants, and technical assistance. 